\title{
Apoptosis of Endothelial Cells by 13-HPODE Contributes to Impairment of Endothelial Barrier Integrity
}

\author{
Valerie E. Ryman, Nandakumar Packiriswamy, and Lorraine M. Sordillo \\ College of Veterinary Medicine, Michigan State University, East Lansing, MI 48824, USA \\ Correspondence should be addressed to Lorraine M. Sordillo; sordillo@msu.edu
}

Received 14 June 2016; Accepted 30 August 2016

Academic Editor: Denis Girard

Copyright ( 2016 Valerie E. Ryman et al. This is an open access article distributed under the Creative Commons Attribution License, which permits unrestricted use, distribution, and reproduction in any medium, provided the original work is properly cited.

Inflammation is an essential host response during bacterial infections such as bovine mastitis. Endothelial cells are critical for an appropriate inflammatory response and loss of vascular barrier integrity is implicated in the pathogenesis of Streptococcus uberis-induced mastitis. Previous studies suggested that accumulation of linoleic acid (LA) oxygenation products derived from 15-lipoxygenase-1 (15-LOX-1) metabolism could regulate vascular functions. The initial LA derivative from the 15-LOX-1 pathway, 13-hydroperoxyoctadecadienoic acid (HPODE), can induce endothelial death, whereas the reduced hydroxyl product, 13-hydroxyoctadecadienoic acid (HODE), is abundantly produced during vascular activation. However, the relative contribution of specific LA-derived metabolites on impairment of mammary endothelial integrity is unknown. Our hypothesis was that $S$. uberis-induced LA-derived 15-LOX-1 oxygenation products impair mammary endothelial barrier integrity by apoptosis. Exposure of bovine mammary endothelial cells (BMEC) to S. uberis did not increase 15-LOX-1 LA metabolism. However, S. uberis challenge of bovine monocytes demonstrated that monocytes may be a significant source of both 13-HPODE and 13-HODE during mastitis. Exposure of BMEC to 13-HPODE, but not 13-HODE, significantly reduced endothelial barrier integrity and increased apoptosis. Changing oxidant status by coexposure to an antioxidant during 13-HPODE treatment prevented adverse effects of 13-HPODE, including amelioration of apoptosis. A better understanding of how the oxidant status of the vascular microenvironment impacts endothelial barrier properties could lead to more efficacious treatments for S. uberis mastitis.

\section{Introduction}

Inflammation contributes to a variety of human and veterinary diseases, including mastitis. Bovine mastitis caused by Streptococcus uberis results in severe damage to milkproducing tissues as a result of an uncontrolled inflammatory response. Previous clinical and histopathological data suggested that disruption of the endothelial barrier contributed to disease pathology. For example, S. uberis intramammary challenge studies reported a loss in the blood-milk barrier as indicated by a sustained increase of plasma proteins in milk [1]. Similarly, histopathological analysis demonstrated that neutrophils accumulated in mammary tissue up to several days after $S$. uberis intramammary challenge indicating an inability of the endothelium to limit leukocyte influx across the blood-milk barrier [2, 3]. Subcutaneous edema after intramammary $S$. uberis challenge also indicated an inability to preserve a selectively permeable vascular barrier [4]. The mechanisms that may cause endothelial dysfunction during S. uberis mastitis are undefined, but some fatty acid-derived oxylipids were implicated in contributing to development of dysfunctional endothelial responses $[5,6]$.

Oxylipids are synthesized from esterified polyunsaturated fatty acids (PUFA) that are cleaved from the phospholipid membrane by cytosolic phospholipase $A_{2}$. Cleaved PUFA are often oxidized through several different enzymatic pathways including 15-lipoxygenase (15-LOX) [7, 8]. Initial enzymatic oxygenation products can be further enzymatically metabolized by a variety of downstream enzymes including hydrolases and dehydrogenases [9, 10]. Additionally, initial oxygenation products during oxylipid biosynthesis may be reduced depending on the redox status of the cellular environment. For example, enzymatic oxidation of linoleic acid (LA) by 15-LOX-1 predominately yields 
13-hydroperoxyoctadecadienoic acid (13-HPODE) and can be reduced to 13-hydroxyoctadecadienoic acid (13-HODE) by antioxidants and reducing agents, such as glutathione [11]. Dehydrogenation of 13-HODE to an anti-inflammatory 13-oxooctadecadienoic acid (13-oxoODE) can occur by the action of NADPH-dependent fatty acid dehydrogenases [9]. Since LA oxidation and metabolism is a sequential process, 13-HPODE biosynthesis is required for the subsequent generation of 13-HODE and 13-oxoODE. Current literature supports an important role for some LA-derived 15-LOX-1 oxylipids in a normal inflammatory response [12-14]. However, previous data also suggested 13-HPODE biosynthesis induced death of various cell types and was associated with the pathology of severe inflammatory based diseases $[15,16]$.

A recently published study by the current authors proposed that LA-derived oxylipids might be responsible for contributing to S. uberis pathogenesis [17]. Authors specifically highlighted the potential contribution of the 15-LOX1 oxidation pathway to disruption of the endothelial barrier [17]. Various studies showed that 13-HODE induced vascular activation and could play a role in regulating endothelial barrier integrity during inflammation $[6,18]$. The initial 15LOX-1 LA oxygenation product, 13-HPODE, was implicated in contributing to apoptosis of endothelial cells, which could be a key event contributing to endothelial dysfunction [19-21]. However, the capacity of specific LA oxygenation products to compromise the mammary endothelial barrier during S. uberis mastitis is unknown. Thus, the hypothesis for the current study was that $S$. uberis-induced LA-derived 15LOX-1 oxygenation products impair mammary endothelial barrier integrity by apoptosis.

\section{Materials and Methods}

2.1. Reagents. High performance liquid chromatography(HPLC-) grade acetonitrile, HPLC-grade methanol, formic acid, sodium selenite, insulin, heparin, transferrin, ethylenediaminetetraacetic acid (EDTA), triphenylphosphine (TPP), sodium selenite, soybean lipoxidase type $\mathrm{V}$, and linoleic acid were purchased from Sigma-Aldrich (St. Louis, MO). Diethyl ether and butylated hydroxy toluene (BHT) were purchased from ACROS Organics (Fair Lawn, NJ). YOPRO1 and propidium iodide stains were from Thermo Fisher Scientific (Waltham, MA). Antibiotics/antimycotics, trypsinEDTA, glutamine, and bovine collagen were from Life Technologies (Carlsbad, CA). All predesigned bovine TaqMan ${ }^{\circledR}$ primers were purchased from Applied Biosystems (Foster City, CA). Deuterated oxylipid standards, nondeuterated oxylipid standards, and indomethacin were purchased from Cayman Chemical (Ann Arbor, MI). Magnesium sulfate was purchased from Avantor Performance Materials, Inc. (Central Valley, PA), and sodium borate from Fisher Science Education (Nazareth, PA). Fetal bovine serum was purchased from Hyclone Laboratories, Inc. (Logan, Utah). The HEPES buffer, HAM's F-12k, and RPMI 1640 were from Corning Inc. (Corning, NY).

2.2. Preparation of Streptococcus uberis for In Vitro Challenge. Streptococcus uberis was streaked onto a blood agar plate to enable collection of 3 pure colony forming units (CFU). The $3 \mathrm{CFU}$ were added to $100 \mathrm{~mL}$ RPMI 1640 medium containing $5 \%$ fetal bovine serum (FBS), $300 \mathrm{mg} / \mathrm{mL}$ L-glutamine, and $0.1 \mu \mathrm{M}$ sodium selenite. The suspension was shaken at $37^{\circ} \mathrm{C}$ for $13 \mathrm{hr}$. For BMEC challenge experiments, the bacterial suspension was centrifuged at $11,000 \times \mathrm{g}$ for $30 \mathrm{~min}$ at $4^{\circ} \mathrm{C}$. After centrifuging, the supernatant was filtered through a filter with a pore size of $0.22 \mu \mathrm{M}$. For monocyte challenge experiments, filtered supernatant was utilized as described and also bacterial suspension was heat-killed in a $65^{\circ} \mathrm{C}$ water bath for $45 \mathrm{~min}$. Efficacy of heat-killing was determined by restreaking neat bacterial suspension onto a blood agar plate and incubating at $37^{\circ} \mathrm{C}$ to confirm absence of $S$. uberis growth.

\subsection{Primary Bovine Cell Isolation and Culture}

2.3.1. Isolation and Culture of Primary Bovine Mammary Endothelial Cells (BMEC). Mammary endothelial cells were collected from the supramammary artery of healthy Holstein dairy cows based on techniques described previously [22]. The BMEC were purified by limited cloning techniques and then cultured in BMEC media containing Ham's F$12 \mathrm{~K}$ medium containing 10\% FBS, $20 \mathrm{mM}$ HEPES, antibiotics and antimycotics (100 U/mL consisting of penicillin, streptomycin, and amphotericin B), heparin $(100 \mu \mathrm{g} / \mathrm{mL})$, insulin $(10 \mu \mathrm{g} / \mathrm{mL})$, transferrin $(5 \mu \mathrm{g} / \mathrm{mL})$, and sodium selenite $(10 \mathrm{ng} / \mathrm{mL})$. Cells were revived from liquid nitrogen at pass 4 and used up to passage 10. For experiments involving exposure to $S$. uberis, cells were seeded the day before at $2.5 \times$ $10^{6}$ cells $/ 100 \mathrm{~mm}$ cell culture dish. The $S$. uberis supernatant was diluted 1:3 in BMEC media for challenge. At time of challenge, all media were aspirated from $100 \mathrm{~mm}$ dishes and replaced with diluted $S$. uberis supernatant. The BMEC then were incubated for $4 \mathrm{hr}$ and $36 \mathrm{hr}$ at $37^{\circ} \mathrm{C}$. Lipopolysaccharide (LPS) at $25 \mathrm{ng} / \mathrm{mL}$ was added for $4 \mathrm{hr}$ as a positive control.

\subsubsection{Isolation and Culture of Primary Bovine Monocytes.} Peripheral blood mononuclear cells (PBMC) were collected from healthy Holstein dairy cows by methods previously described [23]. Primary monocytes were isolated from PBMC by the plate adherence method in RPMI 1640 medium containing $5 \%$ fetal bovine serum (FBS), $300 \mathrm{mg} / \mathrm{mL} \mathrm{L-}$ glutamine, antibiotics and antimycotics $(100 \mathrm{U} / \mathrm{mL}$ consisting of penicillin, streptomycin, and amphotericin B), and $0.1 \mu \mathrm{M}$ sodium selenite [24]. The PBMC and monocytes were collected and prepared fresh for each replicate. For S. uberis challenge of monocytes, PBMC were seeded at a concentration of $8 \times 10^{7}$ cells $/ 100 \mathrm{~mm}$ cell culture dish with approximately $10 \%$ cell adherence after $3 \mathrm{hr}$ incubation at $37^{\circ} \mathrm{C}$ and 3 subsequent washes. Percentage of monocytes from adherent cell population was assessed by flow cytometry based on previous work in our lab [25] and in the current study was approximately $75 \%$ monocytes. After the washes, either S. uberis supernatant or heat-killed S. uberis was added for $4 \mathrm{hr}$ and $36 \mathrm{hr}$. The multiplicity of infection for heat-killed S. uberis challenge was an average of 54:1. The S. uberis supernatant was diluted $1: 3$ for challenge. Monocytes were incubated for $4 \mathrm{hr}$ and $36 \mathrm{hr}$ at $37^{\circ} \mathrm{C}$. Lipopolysaccharide at $25 \mathrm{ng} / \mathrm{mL}$ was added for $4 \mathrm{hr}$ as a positive control. 
TABLE 1: Bovine primers for qRT-PCR.

\begin{tabular}{lcc}
\hline Gene $^{\mathrm{a}}$ & Reference sequence & TaqMan assay ID \\
\hline$T B P$ & NM_001075742.1 & Bt03241946_ml \\
$P G K 1$ & NM_001034299.1 & Bt03225857_ml \\
$A C T B$ & NM_173979.3 & Bt03279174_gl \\
$I C A M-1$ & NM_174348.2 & Bt03213911_m1 \\
$V C A M-1$ & NM_174484.1 & Bt03279189_ml \\
$I L-6$ & NM_173923.2 & Bt03211905_ml \\
$I L-8$ & NM_173925.2 & Bt03211906_ml \\
$I L-10$ & NM_174088.1 & Bt03212727_m1 \\
$i N O S$ & M_001076799.1 & Bt03249581_m1 \\
15-LOX-1 & NM_174501.2 & Bt03214775_m1 \\
$C O X-2$ & NM_174445.2 & Bt03214492_m1 \\
\hline
\end{tabular}

${ }^{a}$ TBP: TATA-box binding protein; PGK1: phosphoglycerate kinase; ACTB: $\beta$-actin; ICAM-1: intercellular adhesion molecule-1; VCAM-1: vascular adhesion molecule-1; IL: interleukin, iNOS: inducible nitric oxide synthase; 15-LOX-1: 15-lipoxygenase-1; COX-2: cyclooxygenase-2.

${ }^{\mathrm{b}}$ Applied Biosystems Foster City, CA.

2.4. Primary BMEC and Monocyte mRNA Quantification. Total mRNA was isolated with the RNeasy Mini Kit (Qiagen, Venlo, Limburg) following the manufacturer's instructions. The qRT-PCR was completed using predesigned TaqMan minor groove binding primers with FAM probe from Applied Biosystems (Table 1). Reaction mixtures included TaqMan Gene Expression Master Mix, cDNA, and TaqMan Gene Expression Assay Mix that contained primer for gene of interest. Samples were run in triplicate with $\beta$-actin, TATAbox binding protein (TBP), and phosphoglycerate kinase 1 (PGK1) as endogenous controls. Target genes to assess BMEC inflammatory phenotype were cyclooxygenase-2 (COX-2), 15-LOX-1, vascular cell adhesion molecule-1, intercellular adhesion molecule-1, and interleukin-8 (IL-8). Thermal cycling conditions for BMEC were as follows: stage $1,95^{\circ} \mathrm{C}$ for $20 \mathrm{~s}$; stage $2,95^{\circ} \mathrm{C}$ for $3 \mathrm{~s}$; stage $3,60^{\circ} \mathrm{C}$ for $30 \mathrm{~s}$, with 40 replications through stages 2 and 3. Primary monocyte cDNA required amplification and was amplified using TaqMan PreAmp Kit (Applied Biosystems Inc.). Target genes to assess monocyte inflammatory phenotype were COX-2, 15-LOX1, inducible nitric oxide synthase (iNOS), IL-10, and IL-6. Thermal cycling conditions for monocytes were as follows: stage 1: $50^{\circ} \mathrm{C}$ for $2 \mathrm{~min}$, stage $2: 95^{\circ} \mathrm{C}$ for $10 \mathrm{~min}$, stage $3: 95^{\circ} \mathrm{C}$ for $15 \mathrm{~s}$, and stage $4: 60^{\circ} \mathrm{C}$ for $1 \mathrm{~min}$, with 40 replicates of stages 3 and 4 . Gene expression was calculated using $\Delta \mathrm{Ct}$ method for statistical analysis and also using $2^{-\Delta \Delta C t}$ method for graphical purposes [26, 27].

2.5. Extraction and Quantification of Oxylipids. Oxylipids were extracted from the supernatant after S. uberis challenge in monocytes and BMEC based on techniques previously described [28]. Briefly, supernatant was collected and an antioxidant reducing agent at $4 \mu \mathrm{L} / \mathrm{mL}$ and a mixture of internal standards containing $0.01 \%$ formic acid was added. Antioxidant and reducing agent was prepared with 50\% $\mathrm{MeOH}, 25 \% \mathrm{EtOH}$, and 25\% HPLC-grade water containing $0.54 \mathrm{mM}$ EDTA $0.9 \mathrm{mM}$ BHT, $3.2 \mathrm{mM}$ TPP, and
$5.6 \mathrm{mM}$ indomethacin. The internal standards mixture contained the following deuterated oxylipids $(0.1 \mathrm{ng} / \mu \mathrm{L}, 10 \mathrm{ng}$ total): $\mathrm{LTB}_{4-d 4}, \mathrm{TxB}_{2-d 4}, \mathrm{PGF}_{2 \alpha-d 4}, \mathrm{PGE}_{2-d 4}, \mathrm{PGD}_{2-d 4}, 13(\mathrm{~S})-$ $\mathrm{HODE}_{-d 4}$, 6-keto $\mathrm{PGF}_{1 \alpha-d 4}, 9(\mathrm{~S})-\mathrm{HODE}_{-d 4}, 12(\mathrm{~S})-\mathrm{HETE}_{-d 8}$, and $15(\mathrm{~S})-\mathrm{HETE}_{-d 8}$. The solution was brought up to $60 \%$ $(\mathrm{v} / \mathrm{v})$ methanol to facilitate protein precipitation. Samples were centrifuged at $4000 \times \mathrm{g}$ for $30 \mathrm{~min}$ at $4^{\circ} \mathrm{C}$. Supernatant was aspirated and diluted to $5 \%(\mathrm{v} / \mathrm{v})$ methanol and kept cold prior to extraction through column cartridges prior to passing samples. the Phenomenex Strata-X 33u Polymeric Reverse-Phase Columns (500 mg/12 mL, Phenomenex, Torrance, CA) were conditioned with $6 \mathrm{~mL}$ methanol then $6 \mathrm{~mL}$ water. After conditioning, samples were run through the column and then washed with $40 \%$ methanol. The column was dried completely and then oxylipids were eluted from the columns in methanol/acetonitrile (50:50; v/v). Samples were dried in a Savant SVD121P SpeedVac (Thermo Scientific, Waltham, MA), resuspended in acetonitrile/water/formic acid $(37: 63: 0.02 ; \mathrm{v} / \mathrm{v} / \mathrm{v})$, and centrifuged at $14,000 \times \mathrm{g}$ for $30 \mathrm{~min}$. Supernatant was aspirated and transferred to chromatography vials prior to liquid chromatography-mass spectrometry (LC-MS) quantification. Oxylipids were quantified according to previously described methods [17].

2.6. Preparation of 13-HPODE. The 13-HPODE was prepared according to previous reports with modifications on a Shimadzu LC-photo diode array detector system (Kyoto, Japan) [29]. Briefly, $30 \mathrm{~mL} 0.15 \mathrm{M}$ ( $\mathrm{pH}$ 9) sodium borate buffer was mixed with $50 \mathrm{mg}$ of LA and 300,000 U of soybean lipoxidase type V. The suspension was stirred for $1 \mathrm{~h}$ on ice. The oxidation reaction was stopped by lowering the $\mathrm{pH}$ to 3 with $1 \mathrm{~N}$ $\mathrm{HCl}$. Immediately, $60 \mathrm{~mL}$ HPLC diethyl ether was added and extracts were washed with $30 \mathrm{~mL}$ water. After separation and dispensing of water, the extracts were dried over magnesium sulfate to remove remaining water. Extracts were resuspended in $2 \mathrm{~mL}$ of HPLC-grade hexane : isopropanol $(96.1: 3.9 \mathrm{v} / \mathrm{v})$ and injected in $200 \mu \mathrm{L}$ aliquots onto a $250 \times 4.6 \mathrm{~mm}$ Luna column (Phenomenex, Torrance, CA) at room temperature. The prepared 13-HPODE fraction was collected based on preinjected 13-HPODE standard. The method used an isocratic mobile phase (hexane : isopropanol, $96.1: 3.9 \mathrm{v} / \mathrm{v}$ ) with a flow rate of $6 \mathrm{~mL} / \mathrm{min}$. A linear 13-HPODE standard curve (0.48$300 \mu \mathrm{M})$ was generated on a reverse-phase LC on a Waters Acquity UPLC BEH C18 $1.7 \mu \mathrm{M}$ column $(2.1 \times 100 \mathrm{~mm})$. The flow rate was $0.6 \mathrm{~mL} / \mathrm{min}$ at $35^{\circ} \mathrm{C}$ and the quadrupole $\mathrm{MS}$ was in electrospray negative ionization mode. The voltage was $-3 \mathrm{kV}$ with the turbo ion spray source temperature at $450^{\circ} \mathrm{C}$. The mobile phase was acetonitrile:MeOH: water:formic acid (47.4:15.8:26.8:0.01 v/v/v/v) and had an analysis time of $10 \mathrm{~min}$. The concentration of 13-HPODE in the synthesized and collected fraction was quantified by Waters Empower $\mathrm{Z}$ software (Waters, Milford, MA) according to the 5-point standard curve.

2.7. Electric Cell-Substrate Impedance Sensing Assay: Endothelial Barrier Integrity. For assessment of endothelial barrier integrity, BMEC were plated on bovine collagen-coated wells with gold electrodes and grown to confluence. Electric currents passing through the monolayer were continuously 
measured by the Electric Cell-Substrate Impedance Sensing system (ECIS, Applied Biophysics, Inc., Troy, NY). Approximately $4-6 \mathrm{hr}$ prior to treatment addition, media were changed to $0 \%$ FBS Ham's F12k media containing $20 \mathrm{mM}$ HEPES, antibiotics and antimycotics $(100 \mathrm{U} / \mathrm{mL}$ consisting of penicillin, streptomycin, and amphotericin B), heparin $(100 \mu \mathrm{g} / \mathrm{mL})$, insulin $(10 \mu \mathrm{g} / \mathrm{mL})$, transferrin $(5 \mu \mathrm{g} / \mathrm{mL})$, and sodium selenite $(10 \mathrm{ng} / \mathrm{mL})$. Resistance across the monolayer was monitored up to $24 \mathrm{hr}$ after treatment addition. Resistance was normalized to the time point immediately prior to treatment addition.

2.8. Measurement of Apoptosis and Necrosis. Apoptosis and necrosis of BMEC exposed to 13-HPODE or $\mathrm{H}_{2} \mathrm{O}_{2}$ were measured using costaining with YOPRO-1 and propidium iodide from a commercial kit (Thermo Fisher Scientific, Waltham, MA). Briefly, BMEC were seeded in $100 \mathrm{~mm}$ cell culture dishes overnight. The media were then changed to 0\% FBS media containing $20 \mathrm{mM}$ HEPES, antibiotics and antimycotics $(100 \mathrm{U} / \mathrm{mL}$ consisting of penicillin, streptomycin, and amphotericin B), heparin $(100 \mu \mathrm{g} / \mathrm{mL})$, insulin $(10 \mu \mathrm{g} / \mathrm{mL})$, transferrin $(5 \mu \mathrm{g} / \mathrm{mL})$, and sodium selenite $(10 \mathrm{ng} / \mathrm{mL})$ for approximately $4 \mathrm{hr}$. Treatments were added for $6 \mathrm{hr}$ and $24 \mathrm{hr}$ depending on experiment. Fluorescence was determined by flow cytometry according to manufacturer's protocols. Amount of apoptosis or necrosis was expressed as fold change over media control. Apoptosis was also measured by the Apo$\mathrm{ONE}^{\circledR}$ Homogeneous Caspase-3/7 kit (Promega, Madison, WI) according to manufacturer's protocols at $6 \mathrm{hr}$ after treatment. Amount of apoptosis or necrosis was expressed as fold change over media control.

2.9. Statistical Analysis. Differences in BMEC mRNA expression of select oxylipid biosynthetic enzymes, select adhesion molecules, and a chemotactic cytokine between respective time point controls and treatments (LPS and S. uberis supernatant) were determined by Student's $t$-tests. Differences in oxylipid biosynthesis for BMEC between control and treatments at each time point were tested in the same manner. Similarly, differences in bovine monocyte mRNA expression of select oxylipid biosynthetic enzymes, a marker of monocyte activation, and inflammatory cytokines between respective time point controls and LPS treatments were determined by Student's $t$-tests. Differences between control, S. uberis supernatant, and heat-killed S. uberis among time points were determined by ordinary one-way ANOVA with Tukey's post hoc correction. Differences in oxylipid biosynthesis for bovine monocytes exposed to $S$. uberis supernatant and heat-killed $S$. uberis were tested in the same manner. To determine differences between treatment groups (e.g., control and 13-HPODE) in normalized endothelial resistance across time, two-way repeated measures ANOVA with post hoc Bonferroni's multiple comparisons tests were performed. Fold change in apoptosis and necrosis (flow cytometry and caspase-3/7 activity) following exposure of BMEC to treatments (e.g., 13-HPODE) relative to $0 \%$ FBS media control was determined by ordinary one-way ANOVA with Tukey's post hoc correction. Effect of several doses of $\mathrm{N}$-acetylcysteine coexposure with 13-HPODE was also tested by ordinary one-way ANOVA with Tukey's post hoc correction. Significance set at $P \leq 0.05$ for all tests.

\section{Results}

3.1. S. uberis Exposure Induced Inflammatory Marker Expression, but Not Oxylipid Biosynthetic Enzyme Expression, in $B M E C$. Oxylipid biosynthetic enzyme mRNA expression (COX-2 and 15-LOX-1) was not significantly increased after $4 \mathrm{hr}$ or $36 \mathrm{hr}$ exposure to S. uberis supernatant (Figures 1(a) and $1(\mathrm{~b})$ ). In contrast, the mRNA expression of ICAM-1 and IL- 8 was significantly increased after $4 \mathrm{hr}$ exposure to S. uberis supernatant and VCAM-1 mRNA expression was significantly increased after $36 \mathrm{hr}$ exposure (Figures 1(c), 1(d), and 1(e)). Exposure to LPS (positive control) demonstrated a significant increase in all genes tested after $4 \mathrm{hr}$ (Figure 1).

3.2. BMEC 13-HODE and 13-oxoODE Biosynthesis Were Not Changed following S. uberis Exposure. Exposure to S. uberis did not induce any significant changes in 13-HODE and 13-oxoODE biosynthesis after 4 and $36 \mathrm{hr}$ (Figures 2(a) and 2(b)). Increased 13-oxoODE, but not 13-HODE, was significant after $4 \mathrm{hr}$ LPS exposure (Figure 2(b)).

3.3. S. uberis Exposure Induced Expression of Inflammatory Markers, including Oxylipid Biosynthetic Enzyme Expression, in Bovine Monocytes. The mRNA expression of COX-2 was significantly upregulated relative to control BMEC by the following treatments and time points: $4 \mathrm{hr}$ S. uberis supernatant, $4 \mathrm{hr}$ heat-killed S. uberis, and $36 \mathrm{hr}$ heat-killed S. uberis (Figure 3(a)). The mRNA expression of 15-LOX1 was significantly upregulated by the following treatments and time points relative to control BMEC: $4 \mathrm{hr}$ S. uberis supernatant and $36 \mathrm{hr}$ heat-killed S. uberis (Figure 3(b)). The mRNA expression of iNOS was significantly upregulated relative to control BMEC after $4 \mathrm{hr}$ and $36 \mathrm{hr}$ exposure to both S. uberis supernatant and heat-killed S. uberis (Figure 3(c)). The mRNA expression of IL- 6 was significantly upregulated by the following treatments and time points relative to control BMEC: $4 \mathrm{hr}$ S. uberis supernatant and $36 \mathrm{hr}$ heat-killed $S$. uberis (Figure $3(\mathrm{~d})$ ). The mRNA expression of IL-10 was significantly upregulated relative to control BMEC after $4 \mathrm{hr}$ exposure to heat-killed S. uberis (Figure 3(e)). Exposure to LPS demonstrated a significant increase in all genes tested after $4 \mathrm{hr}$ (Figure 3).

3.4. 13-HODE, but Not 13-oxoODE, Biosynthesis by Bovine Monocytes Was Upregulated following Heat-Killed S. uberis Exposure. Increased 13-HODE, but not 13-oxoODE, was significant after $36 \mathrm{hr}$ heat-killed S. uberis exposure (Figure 4(a)). Exposure to S. uberis supernatant for 4 and $36 \mathrm{hr}$ failed to induce significant changes in 13-HODE and 13-oxoODE biosynthesis (Figures 4(a) and 4(b)). Similarly, exposure of bovine monocytes to LPS for $4 \mathrm{hr}$ did not induce significant changes in 13-HODE and 13-oxoODE biosynthesis (Figures 4(a) and 4(b)).

3.5. Mammary Endothelial Barrier Integrity Is Decreased during 13-HPODE Treatment. Cultured endothelial barrier 


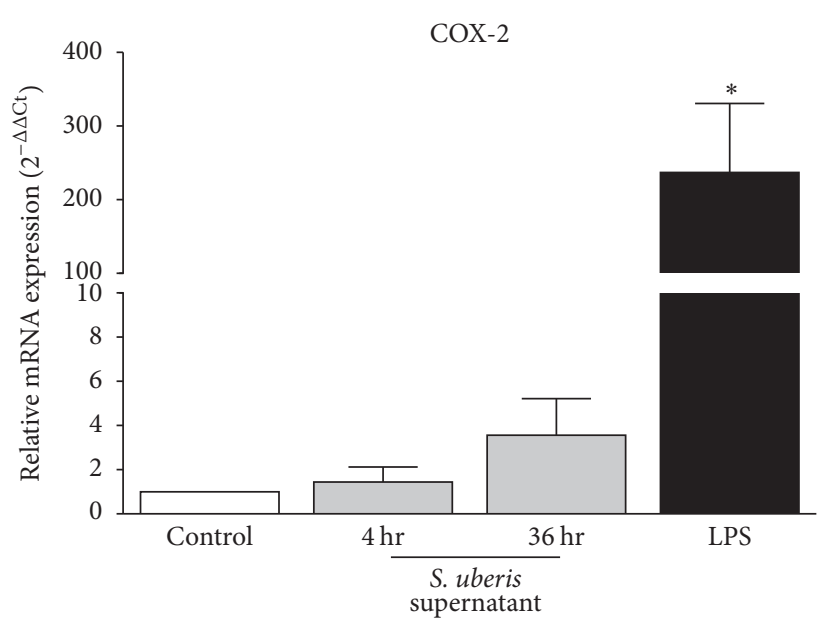

(a)

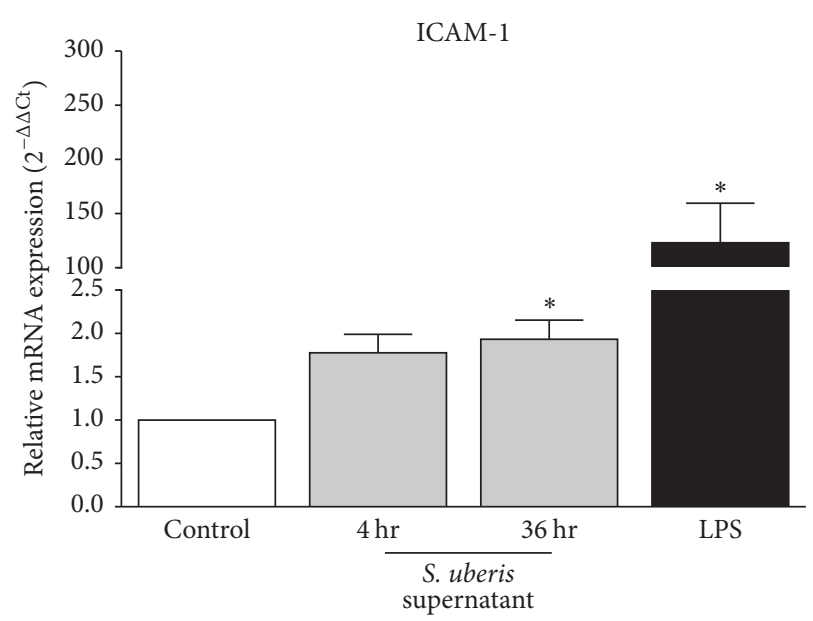

(c)

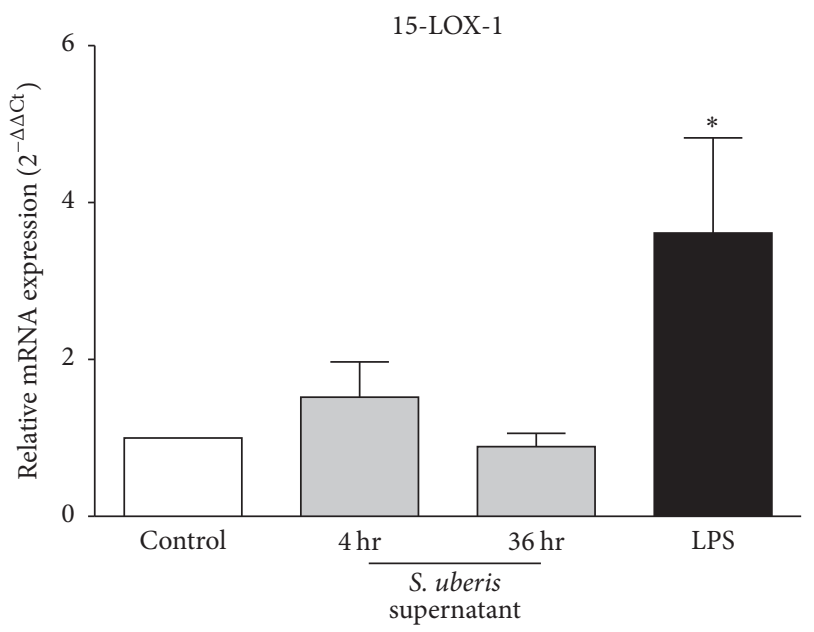

(b)

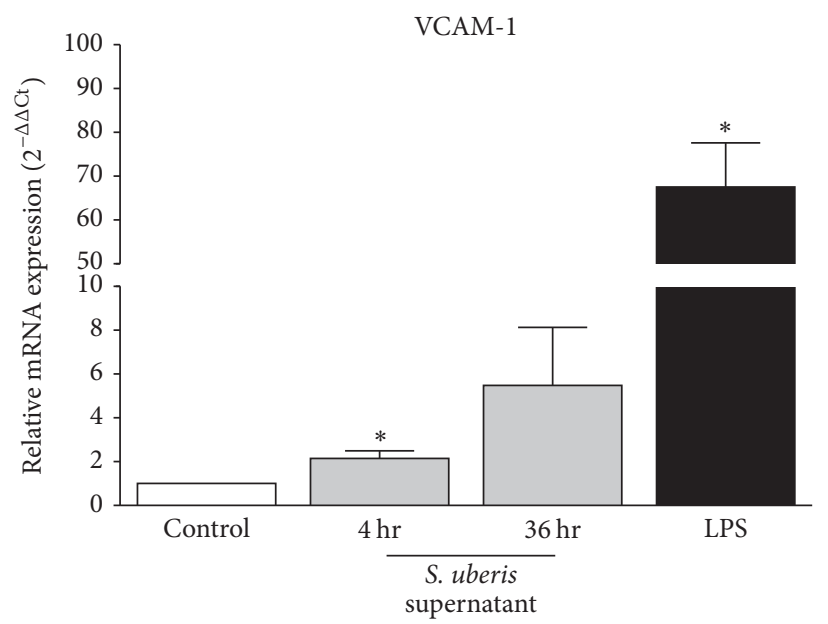

(d)

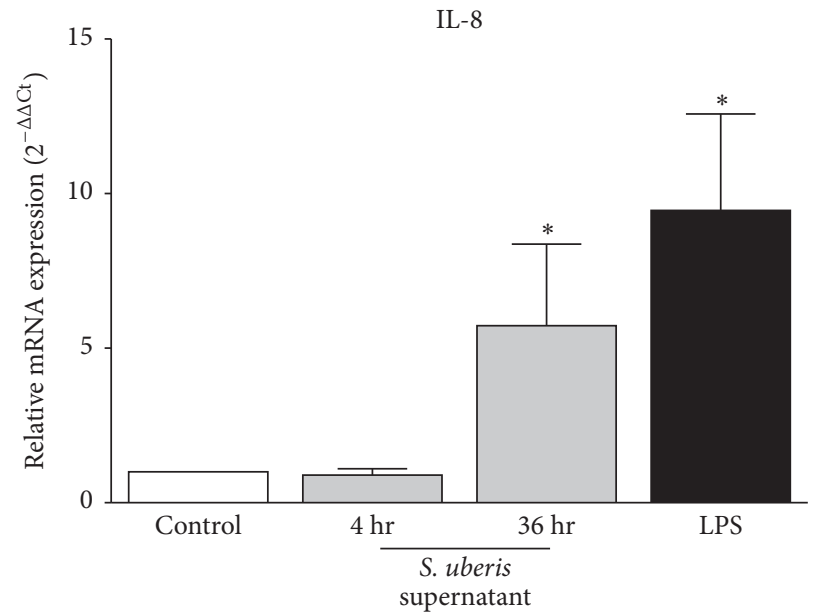

(e)

FIGURE 1: Mean changes in BMEC mRNA expression of oxylipid biosynthetic enzymes (a, b), adhesion molecules (c, d), and a chemotactic cytokine (e). Media controls are displayed as open bars. Positive control is $4 \mathrm{hr}$ lipopolysaccharide (LPS) and displayed in closed bars. Light grey bars represent $S$. uberis supernatant exposure for $4 \mathrm{hr}$ and $36 \mathrm{hr}$. The mRNA expression is expressed as $2^{-\Delta \Delta \mathrm{Ct}} \pm \mathrm{SE}$. Asterisks $(*)$ denote differences between media control and treatments including $S$. uberis and positive control, LPS, as tested by Student's $t$-tests. Significance declared for differences in $\Delta \mathrm{Ct}$ at $P \leq 0.05$ ( $n=3$ for all genes). 


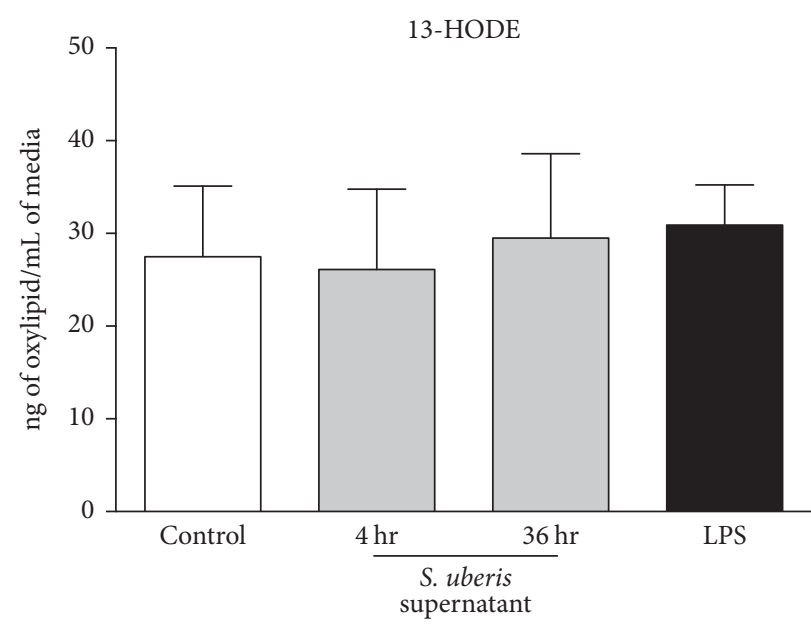

(a)

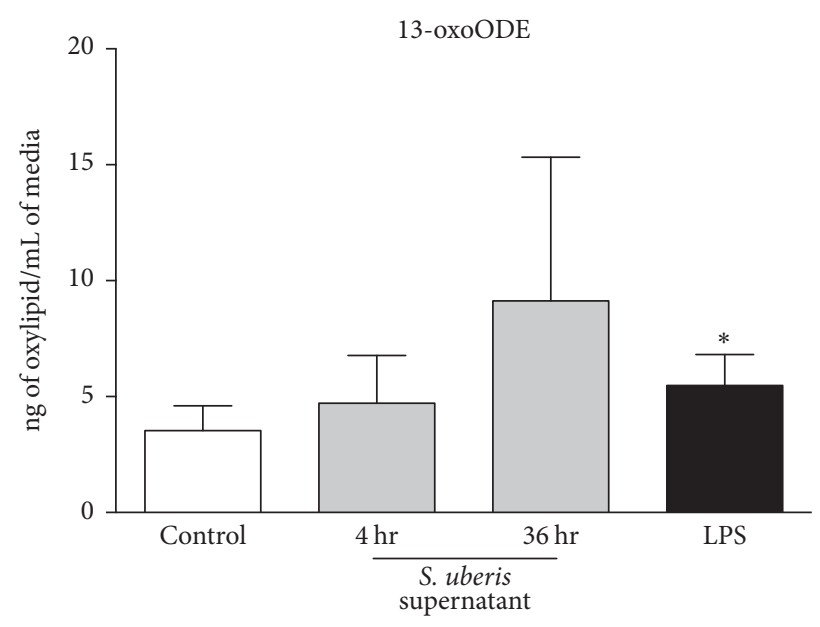

(b)

FIGURE 2: Endothelial oxylipid biosynthesis following $4 \mathrm{hr}$ LPS (black bars) or S. uberis supernatant exposure for $4 \mathrm{hr}$ and $36 \mathrm{hr}$ (light grey bars) is displayed. Media controls are displayed as open bars. Mean oxylipid biosynthesis is expressed as ng of oxylipid/mL of media. Asterisks $(*)$ denote differences between media control and positive control (LPS) as tested by Student's $t$-tests. Significance for differences declared at $P \leq 0.05(n=3)$.

integrity was significantly decreased by $150 \mu \mathrm{M} 13-\mathrm{HPODE}$ from $2 \mathrm{hr}$ after exposure until $12 \mathrm{hr}$ after exposure compared to media control at the respective time points (Figure 5(a)). $6 \mathrm{hr}$ time point and $24 \mathrm{hr}$ time point were used for subsequent determination of apoptosis and necrosis following 13HPODE treatment. Barrier integrity was unchanged during exposure to $100 \mu \mathrm{M}$ 13-HODE (Figure 5(b)). Treatment of endothelial monolayers with $25 \mathrm{ng} / \mathrm{mL}$ LPS was the positive control for all ECIS experiments. Treatment with LPS consistently reduced barrier integrity within $2 \mathrm{hr}$ posttreatment application (Figure 5(c)).

3.6. Apoptosis and Necrosis of BMEC Were Increased during 13-HPODE Treatment. Exposure of BMEC to $150 \mu \mathrm{M} 13-$ HPODE for $6 \mathrm{hr}$ significantly increased YOPRO-1 staining over control indicating an increase in early apoptosis, whereas $0.5 \mu \mathrm{M}$ and $30 \mu \mathrm{M}$ 13-HPODE did not (Figure 6(a)). Similarly, exposure of BMEC to $150 \mu \mathrm{M}$ 13-HPODE for $6 \mathrm{hr}$ significantly increased propidium iodide staining over control indicating an increase in late apoptosis/primary necrosis, but $0.5 \mu \mathrm{M}$ and $30 \mu \mathrm{M}$ 13-HPODE did not (Figure 6(b)). There were no significant differences in apoptosis or necrosis after $24 \mathrm{hr}$ 13-HPODE exposure (Figures 6(c) and 6(d)). Exposure to $2 \mathrm{mM} \mathrm{H}_{2} \mathrm{O}_{2}$ for $1 \mathrm{hr}$ (positive control) demonstrated a significant increase in YOPRO-1 and propidium iodide staining (Figures 6(a) and 6(b)). Exposure of BMEC to $150 \mu \mathrm{M} 13-$ HPODE for $6 \mathrm{hr}$ significantly increased caspase-3/7 activity but $0.5 \mu \mathrm{M}$ and $30 \mu \mathrm{M}$ did not (Figure 7). Exposure to $1 \mathrm{mM}$ $\mathrm{H}_{2} \mathrm{O}_{2}$ for $6 \mathrm{hr}$ (positive control) demonstrated a significant increase in caspase-3/7 activity (Figure 7).

3.7. N-Acetylcysteine Ameliorates 13-HPODE-Induced Apoptosis and Necrosis of BMEC. Coexposure of BMEC to $150 \mu \mathrm{M}$ 13-HPODE and 3 doses of $\mathrm{N}$-acetylcysteine (0.1 mM, $1 \mathrm{mM}$, and $10 \mathrm{mM}$ ) prevented 13-HPODE-induced early apoptosis as demonstrated by decreased YOPRO-1 staining over control
(Figure 8(a)). Coexposure of BMEC to $150 \mu \mathrm{M}$ 13-HPODE and 2 doses of $\mathrm{N}$-acetylcysteine $(1 \mathrm{mM}$ and $10 \mathrm{mM})$ prevented 13-HPODE-induced late apoptosis/early necrosis as demonstrated by decreased propidium iodide staining over control (Figure 8(b)).

3.8. N-Acetylcysteine Rescues 13-HPODE-Induced Impairment of Endothelial Integrity. Coexposure of BMEC monolayer to $150 \mu \mathrm{M} 13$-HPODE and $1 \mathrm{mM} \mathrm{N}$-acetylcysteine prevented a significant decrease in endothelial barrier integrity compared to exposure of $150 \mu \mathrm{M}$ 13-HPODE alone (Figure 9).

\section{Discussion}

Endothelial cells play an active role during an inflammation response to bacteria and bacterial products. Consistent with increased adhesion molecule expression in S. uberis-infected mammary tissue, our data demonstrated increased ICAM1 and VCAM-1 expression in BMEC following exposure to S. uberis supernatant [17]. The observed increase in adhesion molecule expression confirms that BMEC are capable of responding to $S$. uberis exposure. One way in which activated endothelial cells may mediate the inflammatory response is through the enzymatic production of oxylipids through the COX and LOX enzymatic pathways [5, 30, 31]. In contrast to the observed increases in adhesion molecule transcripts, however, expression of COX-2 and 15-LOX-1 mRNA in BMEC was not significantly changed by $S$. uberis exposure [17]. Previous murine studies suggested that COX2 expression was dependent on recognition of pathogen associated molecular patterns by host pathogen receptors, such as Toll-like receptors (TLR) [32]. In the case of $S$. uberis, a recent study demonstrated an inability of heat-killed and live S. uberis to induce TLR-2 signaling in mammary epithelial cells [33]. Though our study did not evaluate TLR activity, failure to activate the BMEC TLR-2 pathway could 


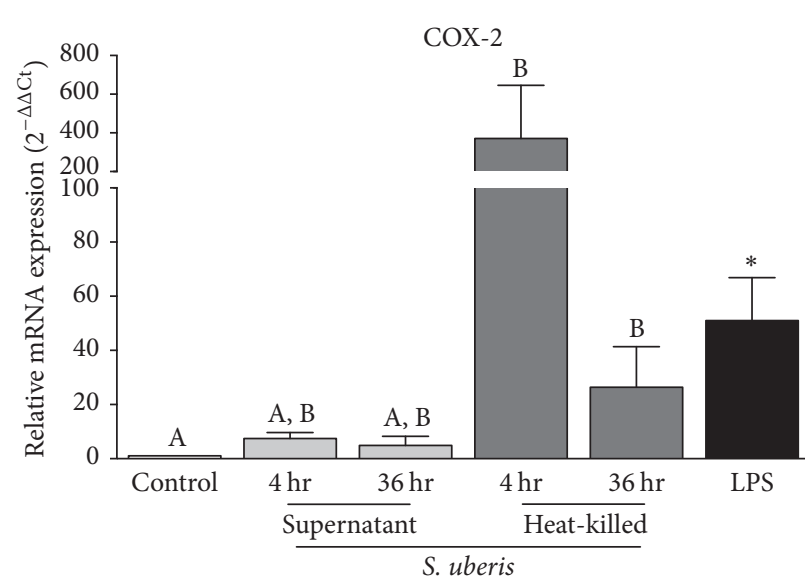

(a)

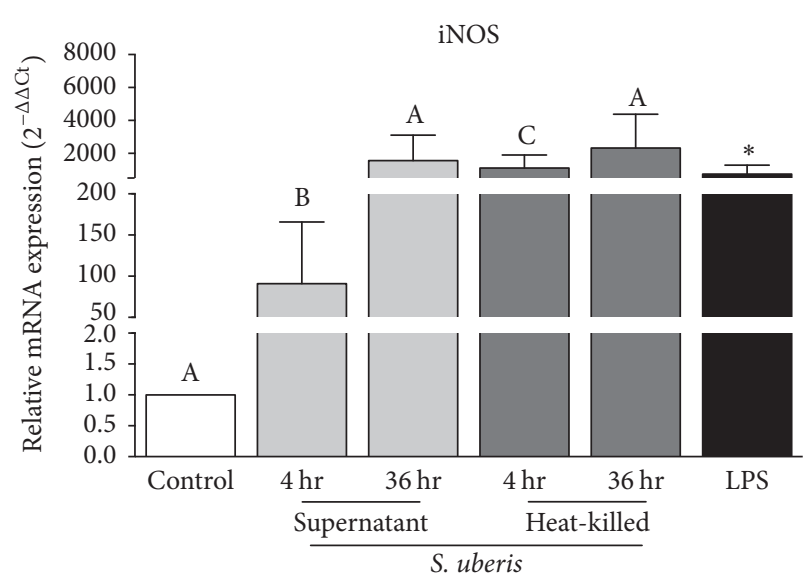

(c)

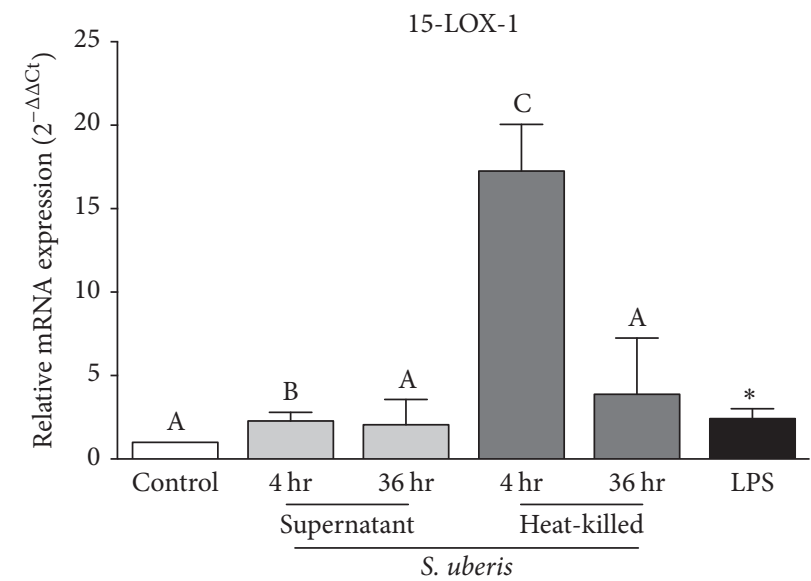

(b)

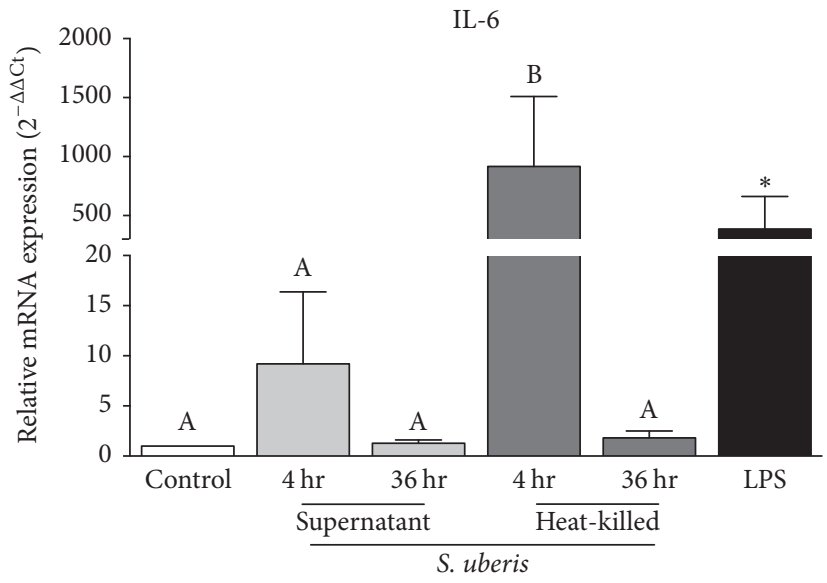

(d)

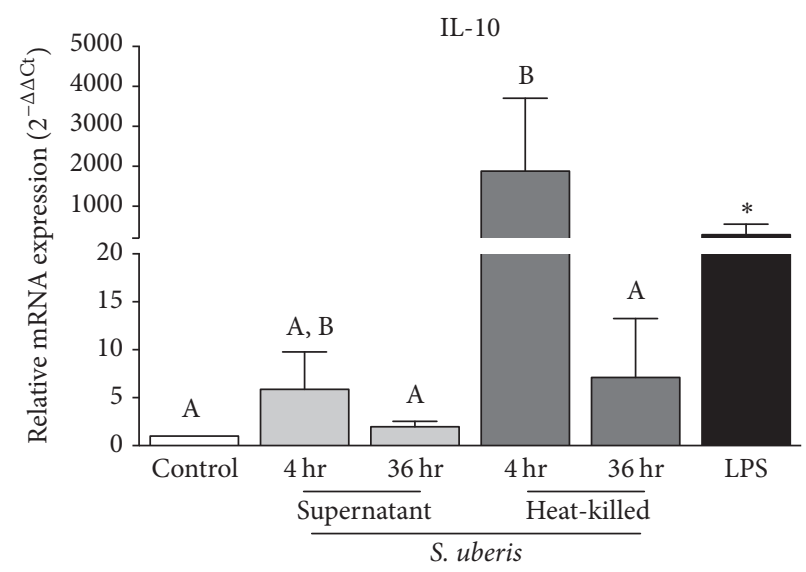

(e)

FIGURE 3: Mean changes in mRNA expression of bovine monocyte oxylipid biosynthetic enzymes (a, b), a marker of monocyte activation (c), and inflammatory cytokines (d, e). Media controls are displayed as open bars. Positive control is 4 hr LPS and displayed in closed bars. Light grey bars represent S. uberis supernatant exposure for $4 \mathrm{hr}$ and $36 \mathrm{hr}$. Dark grey bars represent heat-killed $S$. uberis exposure for $4 \mathrm{hr}$ and $36 \mathrm{hr}$. The mRNA expression is expressed as $2^{-\Delta \Delta \mathrm{Ct}} \pm$ SE. Asterisks $(*)$ denote differences between media control and positive control (LPS) as tested by Student's $t$-tests. Letters that differ between control time points, $4 \mathrm{hr}$ and $36 \mathrm{hr}$ separately, denote significant differences between control and among treatments as measured by an ordinary one-way ANOVA with Tukey's post hoc correction. For example, $4 \mathrm{hr}$ exposure to heat-killed S. uberis upregulated COX-2 mRNA expression compared to control but $4 \mathrm{hr}$ exposure to $S$. uberis supernatant did not (a). Additionally, COX-2 mRNA expression after heat-killed S. uberis exposure is not different from COX-2 mRNA expression after $S$. uberis supernatant exposure (a). A similar relationship can be described for $36 \mathrm{hr}$ exposure of bovine monocytes to heat-killed and $S$. $u b e r i s$ supernatant. Significance declared for all tests using $\Delta$ Ct at $P \leq 0.05$ ( $n=4$ for 15-LOX-1, IL-6, and IL-10; $n=3$ for COX-2 and iNOS). 


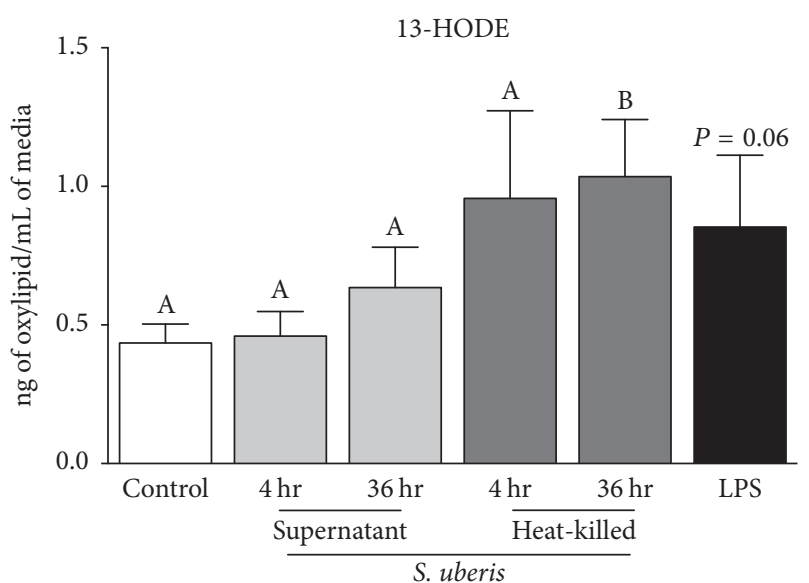

(a)

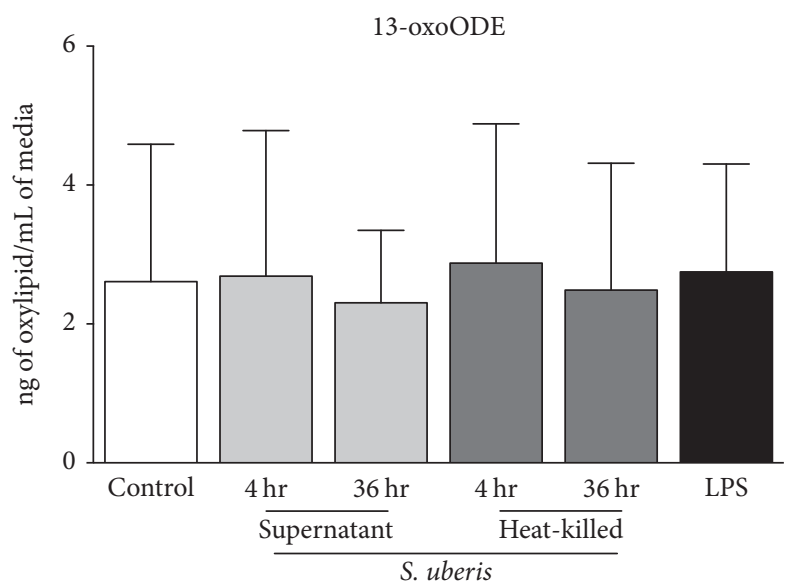

(b)

FIGURE 4: Monocyte oxylipid biosynthesis following $4 \mathrm{hr}$ LPS (black bars) or S. uberis exposure. Media controls are displayed as open bars. Light grey bars represent $S$. uberis supernatant exposure for $4 \mathrm{hr}$ and $36 \mathrm{hr}$. Dark grey bars represent heat-killed $S$. uberis exposure for $4 \mathrm{hr}$ and $36 \mathrm{hr}$. Mean oxylipid biosynthesis is expressed as ng of oxylipid/mL of media. Letters that differ between control time points, $4 \mathrm{hr}$ and $36 \mathrm{hr}$ separately, denote significant differences between control and among treatments as measured by an ordinary one-way ANOVA with Tukey's post hoc correction. For example, $4 \mathrm{hr}$ exposure to $S$. uberis supernatant or heat-killed S. uberis did not modify 13-HODE biosynthesis, whereas $36 \mathrm{hr}$ exposure to heat-killed S. uberis did increase 13-HODE biosynthesis. No letters are displayed in (b) as no differences were detected in any time points. Significance for differences declared at $P \leq 0.05(n=4)$.

result in a failure to induce significant expression of oxylipid biosynthetic enzymes, especially COX-2 and 15-LOX-1. Consistent with no change in 15-LOX-1 mRNA expression after S. uberis supernatant exposure, BMEC did not significantly increase LA-derived oxygenation products from the 15-LOX1 pathway. Additionally, the oxylipid profiles induced by BMEC during S. uberis exposure did not mimic previously described S. uberis-infected mammary tissue profiles [17]. Most importantly, biosynthesis of 13-HODE by BMEC was not increased by $S$. uberis supernatant exposure suggesting that BMEC may not be an important source of oxylipids derived from LA metabolism through the 15-LOX-1 pathway during $S$. uberis mastitis.

Demonstrating that endothelial cells may not be an important source of 13-HODE during S. uberis mastitis required evaluation of other potential cellular sources of oxylipid biosynthesis during an inflammatory response. In murine studies, the macrophages demonstrated the highest expression of 12/15-LOX and represented a significant source of 15-LOX-derived oxylipids [28, 34]. Resident macrophages also are instrumental in alerting the surrounding mammary cells that a perceived insult is present [35]. Therefore, we developed a primary bovine monocyte $S$. uberis challenge model and showed that heat-killed $S$. uberis increased both 15-LOX-1 expression and 13-HODE biosynthesis. Current findings were in contrast to in vivo S. uberis intramammary challenge, which did not demonstrate a significant increase in 15-LOX-1 mRNA expression in S. uberis-infected mammary tissue [17]. Collection of S. uberis-infected tissue may have occurred after peak 15-LOX-1 expression because increased 13-HODE biosynthesis in S. uberis-infected mammary tissue supported increased 15-LOX-1 activity [17]. Additionally, the relative contribution of macrophages expressing 15-LOX-1 compared to mammary epithelial cells and infiltrating neutrophils in infected tissue was not known [3]. Heat-killed $S$. uberis exposure of bovine monocytes induced a significant increase in 13-HODE biosynthesis and may suggest that optimal monocyte 15-LOX-1 activation requires recognition of bacteria by host pathogen recognition receptors [33]. For example, S. uberis supernatant in the current study failed to induce a significant increase in 13-HODE biosynthesis in bovine monocytes as well as BMEC. Nonetheless, our data suggested that bovine monocytes represented a more robust source of both 13-HPODE and 13-HODE during heat-killed S. uberis exposure when compared to mammary endothelial cells. A better understanding of cellular sources of potent lipid mediators within an inflammatory foci could lead to more targeted therapies for the control of certain inflammatory based diseases such as mastitis.

Although LA-derived oxylipids from 15-LOX-1 metabolism were shown to be increased significantly during $S$. uberis mastitis [17], the relative contribution of individual oxylipids to vascular dysfunction has not been identified previously. Our results demonstrated for the first time the capability of 13-HPODE, but not the reduced hydroxyl (13HODE), to modify endothelial monolayer integrity. These findings are not consistent with a previous study that demonstrated that the arachidonic acid-derived hydroxyl (15-hydroxyicosatetraenoic acid, 15-HETE) was capable of reducing bovine microvascular retinal endothelial barrier integrity [36]. In addition to the different substrates from which 15-HETE and 13-HODE are derived, the difference between the effects of arachidonic acid-derived hydroxyls and 13-HODE on barrier integrity could be due to the source of endothelial cells. In this study, BMEC were obtained from the macrovasculature, whereas retinal endothelial cells were 


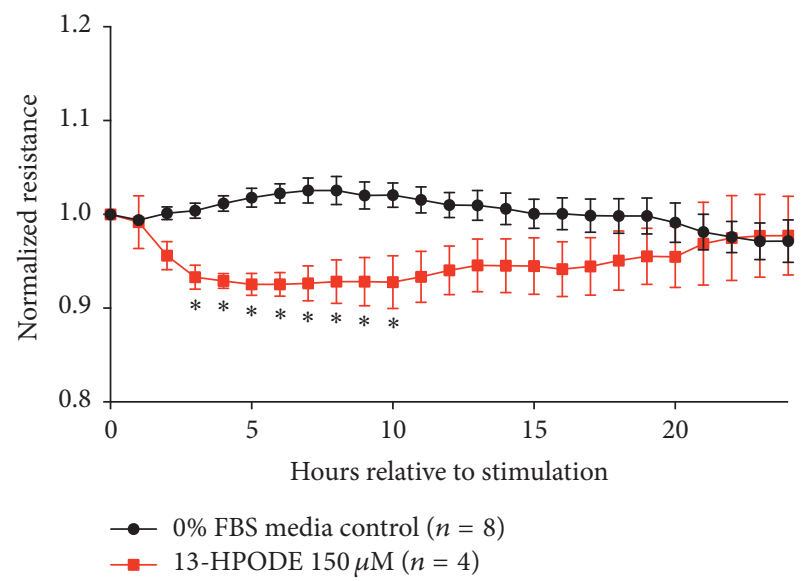

(a)

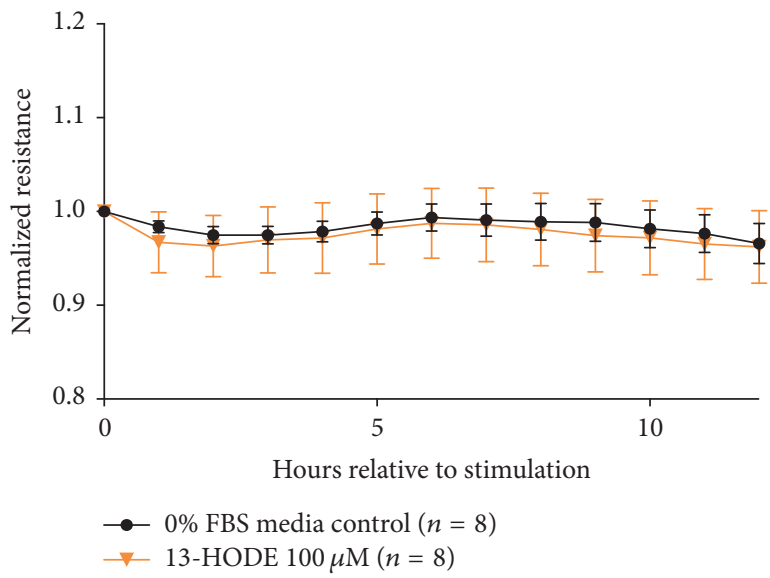

(b)

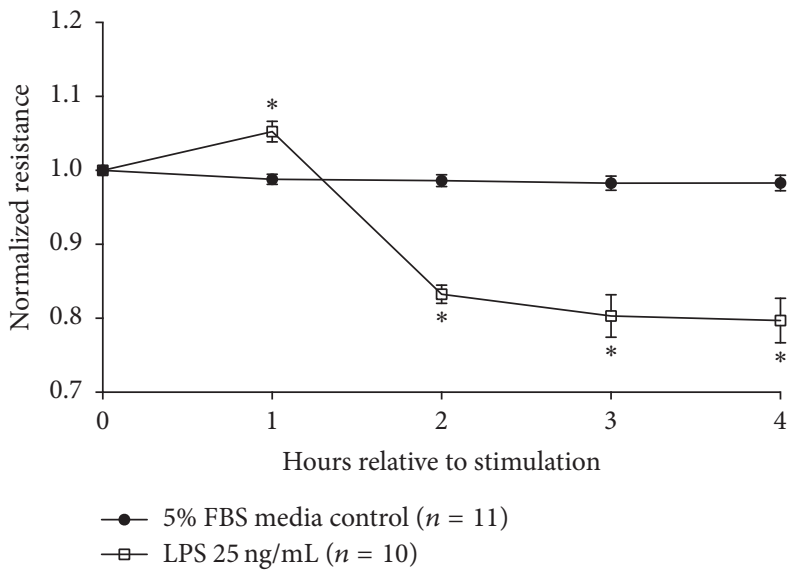

(c)

Figure 5: Mean normalized endothelial resistance across time during media control $(-\bullet)$ and $150 \mu \mathrm{M} 13-\mathrm{HPODE}(--)$ exposure is displayed in (a). Mean normalized resistance for $100 \mu \mathrm{M} 13-\mathrm{HODE}(-)$ exposure up to $6 \mathrm{hr}$ is displayed in (b). Mean normalized resistance across time during media control $(\rightarrow-)$ and $25 \mathrm{ng} / \mathrm{mL}$ LPS $(\rightarrow-)$ is displayed in (c). Resistance of BMEC monolayer across time for each treatment group (control and 13-HPODE, or control and 13-HODE, or control and LPS) was normalized relative to time 0. Significance of differences in resistance across time between treatment groups was tested by a two-way repeated measures ANOVA and adjusted by Bonferroni's multiple comparisons test. An asterisk $(*)$ represents significance declared at $P \leq 0.05$.

isolated from the microvasculature [37]. Thus, the possibility exists that both the fatty acid source of oxylipids and the location of endothelial cells will determine the relative impact of lipid metabolism through the 15-LOX-1 pathway on vascular barrier integrity.

In contrast to 13-HODE, however, we showed that 13HPODE reduced mammary endothelial barrier functions, but the reduction was not sustained throughout the duration of the treatment period. These observations suggest an ability of the endothelial cells to overcome the adverse effects of 13HPODE and that any loss in vascular barrier function may be reversible. During an inflammatory response to bacterial infection, however, there could be repeated exposure to newly synthesized 13-HPODE that may not allow the endothelial barrier to recover. Though we anticipated that 13-HPODE would decrease barrier integrity, confirmation of 13-HODE being unable to modify barrier integrity in our model was essential. Reduction of 13-HPODE generates 13-HODE, and treatment with 13-HPODE would most likely contribute to increased exposure to 13-HODE as well. Other studies have showed differential effects of 13-HPODE and 13-HODE on endothelial activation, but the present study was the first to demonstrate different effects on endothelial monolayer integrity [13]. In support of compromised barrier integrity, additional functional studies would be useful to evaluate how 13-HPODE may contribute to enhanced vascular permeability to macromolecules or uncontrolled leukocyte transmigration.

Apoptosis and necrosis of endothelial cells disrupt the continuous, single-cell layer necessary for orchestrating an effective and self-limiting inflammatory response. The current study demonstrated induction of apoptosis and necrosis of BMEC in conjunction with decreased mammary endothelial barrier integrity. Our findings were consistent with previous work that demonstrated 13-HPODE-induced apoptosis in bovine aortic endothelial cells [19-21]. Though 


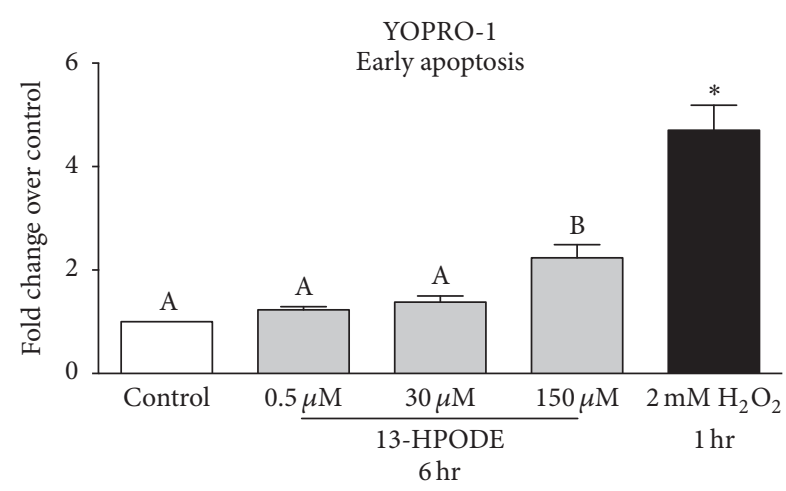

(a)

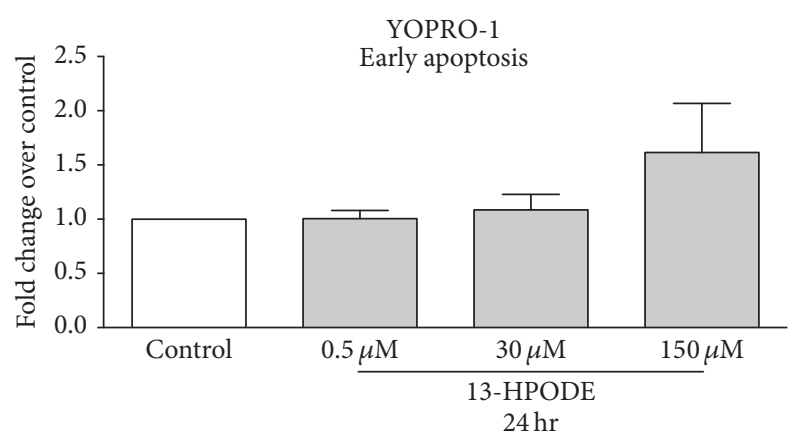

(c)

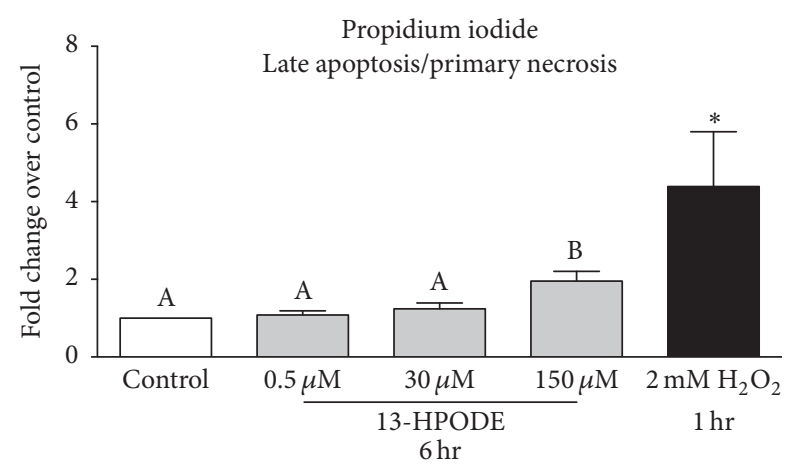

(b)

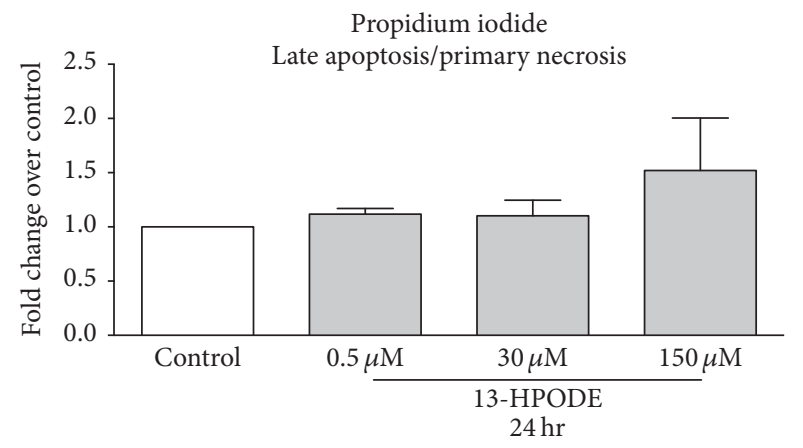

(d)

FIGURE 6: YOPRO ${ }^{\circledR}-1$ and propidium iodide of BMEC staining displayed as fold change over media control after $6 \mathrm{hr}((\mathrm{a})$ and (b)) and $24 \mathrm{hr}$ ((c) and (d)) 13-HPODE exposure. Media controls are displayed in open bars and 13-HPODE treatments are in light grey bars. Positive control (1 hr $2 \mathrm{mM} \mathrm{H}_{2} \mathrm{O}_{2}$ exposure) YOPRO-1 and propidium iodide staining are displayed in (a) and (b) and are the black bars. Different letters demonstrate a significant difference among media control and 13-HPODE treatments determined by one-way ANOVA with Tukey's post hoc correction. An asterisk $(*)$ represents a significant difference between medial control and $\mathrm{H}_{2} \mathrm{O}_{2}$ as determined by Student's $t$-tests. Significance declared at $P \leq 0.05$.

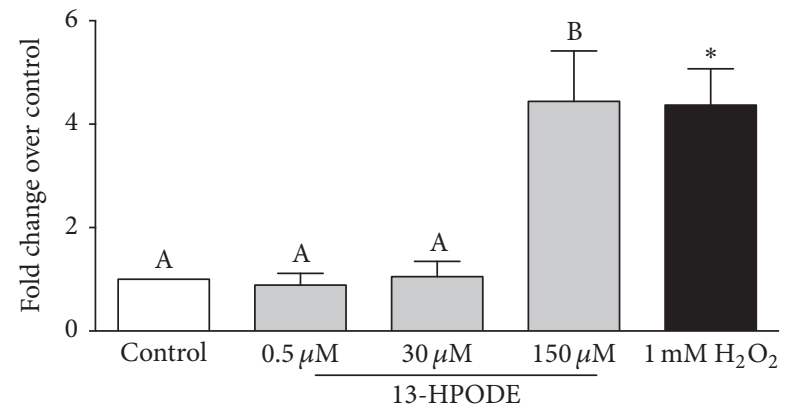

FIGURE 7: Mean change in caspase-3/7 activity of BMEC displayed as fold change over media control (open bar) after $6 \mathrm{hr}$ 13-HPODE (light grey bars) or $1 \mathrm{mM} \mathrm{H}_{2} \mathrm{O}_{2}$ exposure for $6 \mathrm{hr}$ (black bar, positive control). Different letters demonstrate a significant difference among media control and 13-HPODE treatments determined by one-way ANOVA with Tukey's post hoc correction. An asterisk (*) represents a significant difference between medial control and $\mathrm{H}_{2} \mathrm{O}_{2}$ as determined by Student's $t$-tests. Significance declared at $P \leq 0.05$.

not evaluated in the current study, previous data suggested that 13-HPODE activated the intrinsic pathway for apoptosis as a result of mitochondrial dysfunction $[19,20]$. For example, exposure of bovine aortic endothelial cells to 13-HPODE increased the activity of intrinsic pathway caspases 3 and 9 and was associated with a loss in mitochondrial function [20]. The primary proposed mechanism by which 13-HPODE can induce apoptosis is by lipid peroxidation of cell membranes [38]. Phospholipids in cell membranes contain an abundance of esterified PUFA and are extremely susceptible to lipid hydroperoxide attack. Propagation of lipid peroxidation occurs by decomposition of lipid hydroperoxides by transition of metals to generate lipid alkoxyls $\left(\mathrm{LO}^{\circ}\right)$ and lipid peroxyl radicals (LOO ${ }^{\circ}$ [39]. The lipid peroxyl radicals can act as prooxidants and attack membrane-esterified PUFA to generate additional $\mathrm{LO}^{\circ}, \mathrm{LOO}^{\circ}$, and $\mathrm{LOOH}$, such as 13-HPODE. Peroxidation of lipid membranes initiated by extracellular 13-HPODE may contribute to an irreversible increase in mitochondrial permeability and permanent loss of function [39]. Thus preventing accumulation of lipid peroxides and other prooxidants may be protective or beneficial in limiting the effects of 13-HPODE [40]. Overall, the data from the current study demonstrated that shifting oxidant status in the endothelial microenvironment during 13-HPODE treatment by promoting reduction of prooxidants with an antioxidant may limit initiation and propagation of lipid peroxidation, thus preventing apoptosis and impaired barrier integrity. 


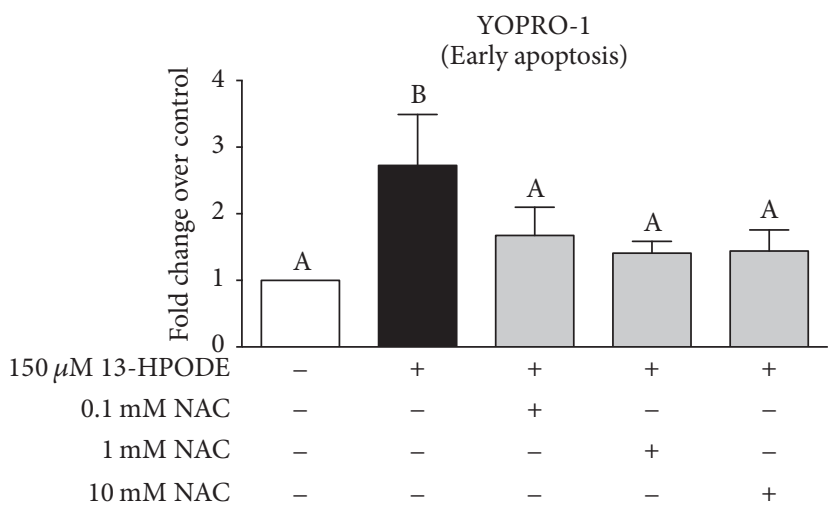

(a)

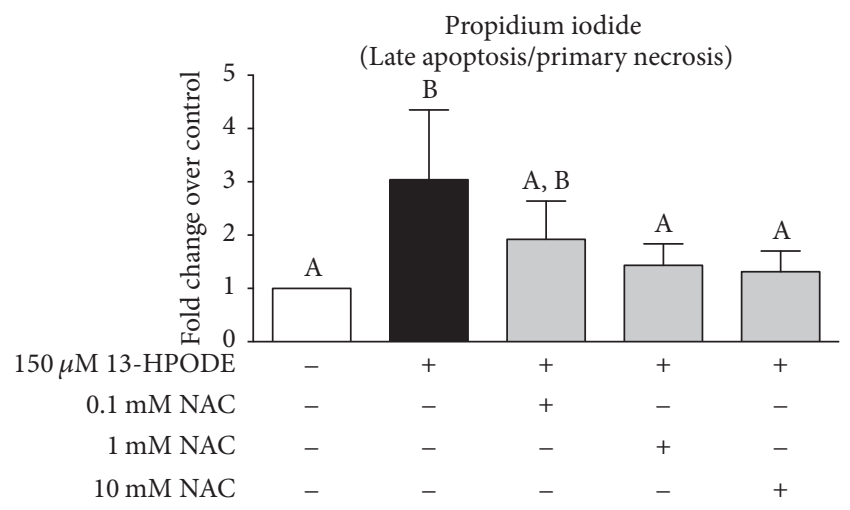

(b)

FIGURE 8: YOPRO-1 and propidium iodide of BMEC staining displayed as fold change over media control (open bar) after 6 hr $150 \mu \mathrm{M} 13-$ HPODE (light grey bars) or $6 \mathrm{hr}$ coexposure with $150 \mu \mathrm{M}$ 13-HPODE or N-acetylcysteine (NAC, light grey bars). Different letters demonstrate a significant difference among media control and treatments as determined by a one-way ANOVA with Tukey's post hoc correction. Significance declared at $P \leq 0.05$.

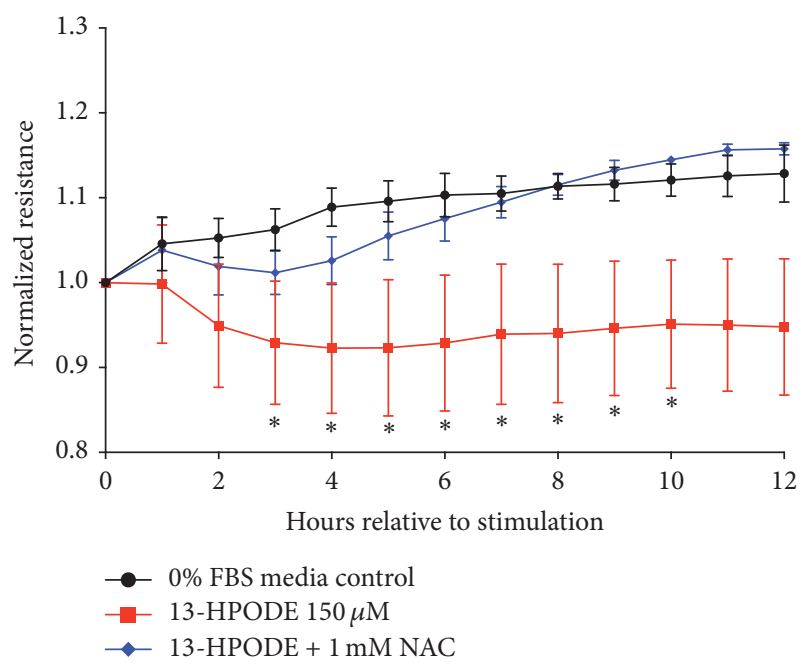

FIGURE 9: Mean normalized endothelial resistance across time during media control (-๑), $150 \mu \mathrm{M} 13-\operatorname{HPODE}(--)$, and $150 \mu \mathrm{M}$ $13-\mathrm{HPODE}+1 \mathrm{mM} \mathrm{N}$-acetylcysteine (NAC) $(-\bullet)$ exposure is displayed in Figure 9. Resistance of BMEC monolayer across time for each treatment group (control, 13-HPODE, and 13-HPODE + NAC) is normalized relative to time 0 . Significance of differences in resistance across time between treatment groups was tested by a two-way repeated measures ANOVA and adjusted by Bonferroni's multiple comparisons test. An asterisk $(*)$ represents significance declared at $P \leq 0.05$. There were no significant differences detected between media control and 13-HPODE + 1 mM NAC.

\section{Conclusions}

The tightly regulated, self-limiting inflammatory response is dependent on optimal endothelial function and maintenance of the endothelial barrier. Some oxylipids may reduce the ability of endothelial cells to orchestrate an optimal inflammatory response. Thus, our study defined a potential source and role for LA-derived 15-LOX-1 metabolites. Our data showed that bovine monocytes, but not BMEC, may be an important source of 15-LOX-1 oxygenation products of LA during $S$. uberis exposure. Furthermore, exposure of BMEC to 13-HPODE, but not 13-HODE, contributed to impaired mammary endothelial barrier integrity and apoptosis of BMEC. We also showed that oxidant status during 13-HPODE treatment may contribute to cell death and barrier integrity. Elucidating the mechanisms by which oxidant status mediates vascular function may be critical to developing targeted therapies for bovine mastitis.

\section{Competing Interests}

The authors declare that they have no competing interests.

\section{Acknowledgments}

The authors acknowledge the technical assistance of Jeff Gandy and Jennifer Devries. This work was funded, in part, through Grants (2011-67015-30179 and 2015-67011-23012) from the Agriculture and Food Research Initiative Competitive Grants Programs of the USDA National Institute for Food and Agriculture and by an endowment from the Matilda R. Wilson Fund (Detroit, MI).

\section{References}

[1] D. D. Bannerman, M. J. Paape, J. P. Goff, K. Kimura, J. D. Lippolis, and J. C. Hope, "Innate immune response to intramammary infection with Serratia marcescens and Streptococcus uberis," Veterinary Research, vol. 35, no. 6, pp. 681-700, 2004.

[2] A. de Greeff, R. Zadoks, L. Ruuls et al., "Early host response in the mammary gland after experimental Streptococcus uberis challenge in heifers," Journal of Dairy Science, vol. 96, no. 6, pp. 3723-3736, 2013.

[3] L. H. Thomas, W. Haider, A. W. Hill, and R. S. Cook, "Pathologic findings of experimentally induced Streptococcus uberis infection in the mammary gland of cows," American Journal of Veterinary Research, vol. 55, no. 12, pp. 1723-1728, 1994. 
[4] L. H. Pedersen, B. Aalbæk, C. M. Røntved et al., "Early pathogenesis and inflammatory response in experimental bovine mastitis due to Streptococcus uberis," Journal of Comparative Pathology, vol. 128, no. 2-3, pp. 156-164, 2003.

[5] L. M. Sordillo, J. A. Weaver, Y.-Z. Cao, C. Corl, M. J. Sylte, and I. K. Mullarky, "Enhanced 15-HPETE production during oxidant stress induces apoptosis of endothelial cells," Prostaglandins and Other Lipid Mediators, vol. 76, no. 1-4, pp. 19-34, 2005.

[6] M. Szklenar, J. Kalkowski, V. Stangl, M. Lorenz, and R. Rühl, "Eicosanoids and docosanoids in plasma and aorta of healthy and atherosclerotic rabbits," Journal of Vascular Research, vol. 50, no. 5, pp. 372-382, 2013.

[7] M. W. Buczynski, D. S. Dumlao, and E. A. Dennis, "Thematic review series: proteomics. An integrated omics analysis of eicosanoid biology," Journal of Lipid Research, vol. 50, no. 6, pp. 1015-1038, 2009.

[8] J. D. Morrow, K. E. Hill, R. F. Burk, T. M. Nammour, K. F. Badr, and L. J. Roberts II, "A series of prostaglandin $\mathrm{F}_{2}-$ like compounds are produced in vivo in humans by a noncyclooxygenase, free radical-catalyzed mechanism," Proceedings of the National Academy of Sciences of the United States of America, vol. 87, no. 23, pp. 9383-9387, 1990.

[9] R. Altmann, M. Hausmann, T. Spöttl et al., "13-Oxo-ODE is an endogenous ligand for PPAR $\gamma$ in human colonic epithelial cells," Biochemical Pharmacology, vol. 74, no. 4, pp. 612-622, 2007.

[10] K. R. Schmelzer, L. Kubala, J. W. Newman, I.-H. Kim, J. P. Eiserich, and B. D. Hammock, "Soluble epoxide hydrolase is a therapeutic target for acute inflammation," Proceedings of the National Academy of Sciences of the United States of America, vol. 102, no. 28, pp. 9772-9777, 2005.

[11] H. Kuhn, S. Banthiya, and K. van Leyen, "Mammalian lipoxygenases and their biological relevance," Biochimica et Biophysica Acta-Molecular and Cell Biology of Lipids, vol. 1851, no. 4, pp. 308-330, 2015.

[12] R. S. Dwarakanath, S. Sahar, M. A. Reddy, D. Castanotto, J. J. Rossi, and R. Natarajan, "Regulation of monocyte chemoattractant protein-1 by the oxidized lipid, 13hydroperoxyoctadecadienoic acid, in vascular smooth muscle cells via nuclear factor-kappa B (NF- $\kappa \mathrm{B})$," Journal of Molecular and Cellular Cardiology, vol. 36, no. 4, pp. 585-595, 2004.

[13] B. Friedrichs, M. Toborek, B. Hennig, L. Heinevetter, C. Müller, and R. Brigelius-Flohé, "13-HPODE and 13-HODE modulate cytokine-induced expression of endothelial cell adhesion molecules differently," BioFactors, vol. 9, no. 1, pp. 61-72, 1999.

[14] P. A. J. Henricks, F. Engels, H. van der Vliet, and F. P. Nijkamp, "9-and 13-hydroxy-linoleic acid posses chemotactic activity for bovine and human polymorphonuclear leukocytes," Prostaglandins, vol. 41, no. 1, pp. 21-27, 1991.

[15] A. Haimovitz-Friedman, C. Cordon-Cardo, S. Bayoumy et al., "Lipopolysaccharide induces disseminated endothelial apoptosis requiring ceramide generation," The Journal of Experimental Medicine, vol. 186, no. 11, pp. 1831-1841, 1997.

[16] D. Hasdai, G. Sangiorgi, L. G. Spagnoli et al., "Coronary artery apoptosis in experimental hypercholesterolemia," Atherosclerosis, vol. 142, no. 2, pp. 317-325, 1999.

[17] V. E. Ryman, G. M. Pighetti, J. D. Lippolis, J. C. Gandy, C. M. Applegate, and L. M. Sordillo, "Quantification of bovine oxylipids during intramammary Streptococcus uberis infection," Prostaglandins \& Other Lipid Mediators, vol. 121, pp. 207-217, 2015.
[18] M. R. Buchanan, T. A. Haas, M. Lagarde, and M. Guichardant, "13-Hydroxyoctadecadienoic acid is the vessel wall chemorepellant factor, LOX," The Journal of Biological Chemistry, vol. 260, no. 30, pp. 16056-16059, 1985.

[19] A. Dhanasekaran, S. Kotamraju, S. V. Kalivendi et al., "Supplementation of endothelial cells with mitochondria-targeted antioxidants inhibit peroxide-induced mitochondrial iron uptake, oxidative damage, and apoptosis," The Journal of Biological Chemistry, vol. 279, no. 36, pp. 37575-37587, 2004.

[20] A. Dhanasekaran, S. Kotamraju, C. Karunakaran et al., "Mitochondria superoxide dismutase mimetic inhibits peroxideinduced oxidative damage and apoptosis: role of mitochondrial superoxide," Free Radical Biology \& Medicine, vol. 39, no. 5, pp. 567-583, 2005.

[21] Y. Tampo, S. Kotamraju, C. R. Chitambar, S. V. Kalivendi, A. Keszler, and J. J. B. Kalyanaraman, "Oxidative stress-induced iron signaling is responsible for peroxide-dependent oxidation of dichlorodihydrofluorescein in endothelial cells role of transferrin receptor-dependent iron uptake in apoptosis," Circulation Research, vol. 92, no. 1, pp. 56-63, 2003.

[22] K. M. Aherne, M. R. Davis, and L. M. Sordillo, "Isolation and characterization of bovine mammary endothelial cells," Methods in Cell Science, vol. 17, no. 1, pp. 41-46, 1995.

[23] G. A. Contreras, N. J. O’Boyle, T. H. Herdt, and L. M. Sordillo, "Lipomobilization in periparturient dairy cows influences the composition of plasma nonesterified fatty acids and leukocyte phospholipid fatty acids," Journal of Dairy Science, vol. 93, no. 6, pp. 2508-2516, 2010.

[24] N. J. O’Boyle, G. A. Contreras, S. A. Mattmiller, and L. M. Sordillo, "Changes in glucose transporter expression in monocytes of periparturient dairy cows," Journal of Dairy Science, vol. 95, no. 10, pp. 5709-5719, 2012.

[25] E. Kabara, L. M. Sordillo, S. Holcombe, and G. A. Contreras, "Adiponectin links adipose tissue function and monocyte inflammatory responses during bovine metabolic stress," Comparative Immunology, Microbiology and Infectious Diseases, vol. 37, no. 1, pp. 49-58, 2014.

[26] S. L. Aitken, C. M. Corl, and L. M. Sordillo, "Pro-inflammatory and pro-apoptotic responses of TNF- $\alpha$ stimulated bovine mammary endothelial cells," Veterinary Immunology and Immunopathology, vol. 140, no. 3-4, pp. 282-290, 2011.

[27] W. Raphael, L. Halbert, G. A. Contreras, and L. M. Sordillo, "Association between polyunsaturated fatty acid-derived oxylipid biosynthesis and leukocyte inflammatory marker expression in periparturient dairy cows," Journal of Dairy Science, vol. 97, no. 6, pp. 3615-3625, 2014.

[28] S. A. Mattmiller, B. A. Carlson, J. C. Gandy, and L. M. Sordillo, "Reduced macrophage selenoprotein expression alters oxidized lipid metabolite biosynthesis from arachidonic and linoleic acid," Journal of Nutritional Biochemistry, vol. 25, no. 6, pp. 647654, 2014.

[29] M. O. Funk, R. Isaac, and N. A. Porter, "Preparation and purification of lipid hydroperoxides from arachidonic and $\gamma$ linolenic acids," Lipids, vol. 11, no. 2, pp. 113-117, 1976.

[30] G. A. Contreras, W. Raphael, S. A. Mattmiller, J. Gandy, and L. M. Sordillo, "Nonesterified fatty acids modify inflammatory response and eicosanoid biosynthesis in bovine endothelial cells," Journal of Dairy Science, vol. 95, no. 9, pp. 5011-5023, 2012.

[31] J. A. Weaver, J. F. Maddox, Y. Z. Cao, I. K. Mullarky, and L. M. Sordillo, "Increased 15-HPETE production decreases prostacyclin synthase activity during oxidant stress in aortic 
endothelial cells," Free Radical Biology \& Medicine, vol. 30, no. 3, pp. 299-308, 2001.

[32] M. Fukata, A. Chen, A. Klepper et al., "Cox-2 is regulated by toll-like receptor-4 (TLR4) signaling: role in proliferation and apoptosis in the intestine," Gastroenterology, vol. 131, no. 3, pp. 862-877, 2006.

[33] J. Günther, A. Czabanska, I. Bauer, J. A. Leigh, O. Holst, and H.-M. Seyfert, "Streptococcus uberis strains isolated from the bovine mammary gland evade immune recognition by mammary epithelial cells, but not of macrophages," Veterinary Research, vol. 47, no. 1, article 13, 2016.

[34] Y. Huo, L. Zhao, M. C. Hyman et al., "Critical role of macrophage 12/15-lipoxygenase for atherosclerosis in apolipoprotein E-deficient mice," Circulation, vol. 110, no. 14, pp. 2024-2031, 2004.

[35] S. L. Aitken, C. M. Corl, and L. M. Sordillo, "Immunopathology of mastitis: insights into disease recognition and resolution," Journal of Mammary Gland Biology and Neoplasia, vol. 16, no. 4, pp. 291-304, 2011.

[36] A. Othman, S. Ahmad, S. Megyerdi et al., "12/15-lipoxygenasederived lipid metabolites induce retinal endothelial cell barrier dysfunction: contribution of NADPH oxidase," PLOS ONE, vol. 8, no. 2, article e57254, 2013.

[37] J. J. Kelly, T. M. Moore, P. Babal, A. H. Diwan, T. Stevens, and W. J. Thompson, "Pulmonary microvascular and macrovascular endothelial cells: differential regulation of $\mathrm{Ca}^{2+}$ and permeability," American Journal of Physiology-Lung Cellular and Molecular Physiology, vol. 274, no. 5, pp. L810-L819, 1998.

[38] A. Catalá, "Lipid peroxidation of membrane phospholipids generates hydroxy-alkenals and oxidized phospholipids active in physiological and/or pathological conditions," Chemistry and Physics of Lipids, vol. 157, no. 1, pp. 1-11, 2009.

[39] G. R. Buettner, "The pecking order of free radicals and antioxidants: lipid peroxidation, $\alpha$-tocopherol, and ascorbate," Archives of Biochemistry and Biophysics, vol. 300, no. 2, pp. 535-543, 1993.

[40] N. Hill-Kapturczak, C. Voakes, J. Garcia, G. Visner, H. S. Nick, and A. Agarwal, "A cis-acting region regulates oxidized lipidmediated induction of the human heme oxygenase-1 gene in endothelial cells," Arteriosclerosis, Thrombosis, and Vascular Biology, vol. 23, no. 8, pp. 1416-1422, 2003. 


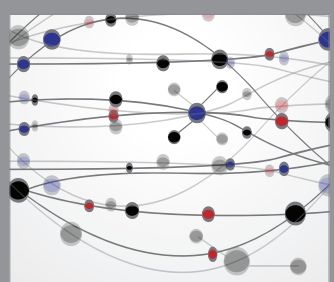

The Scientific World Journal
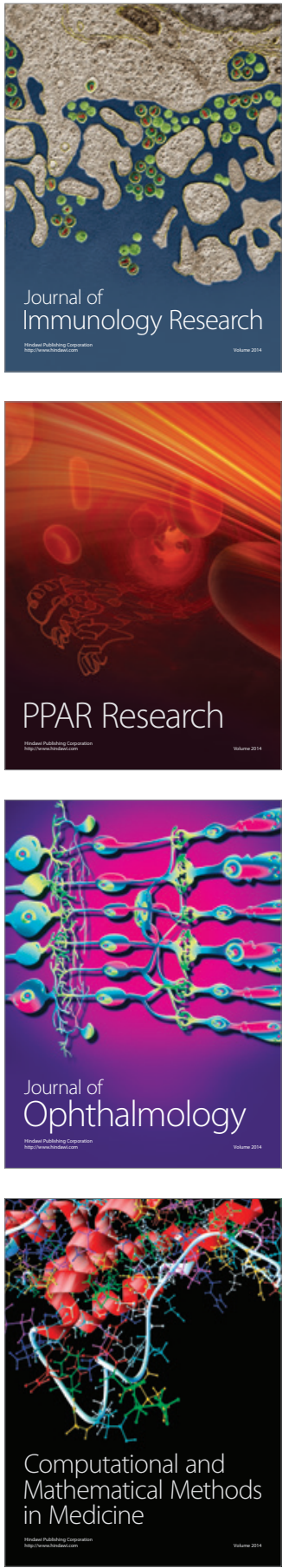

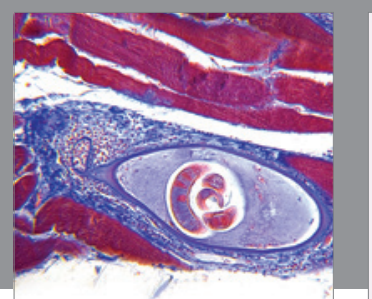

Gastroenterology Research and Practice

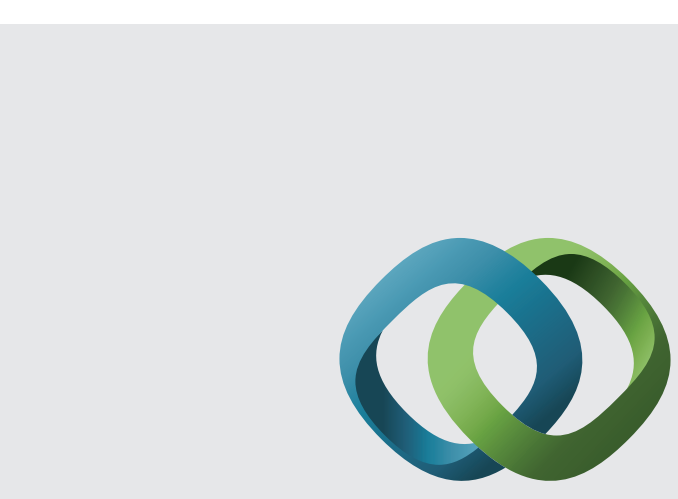

\section{Hindawi}

Submit your manuscripts at

http://www.hindawi.com
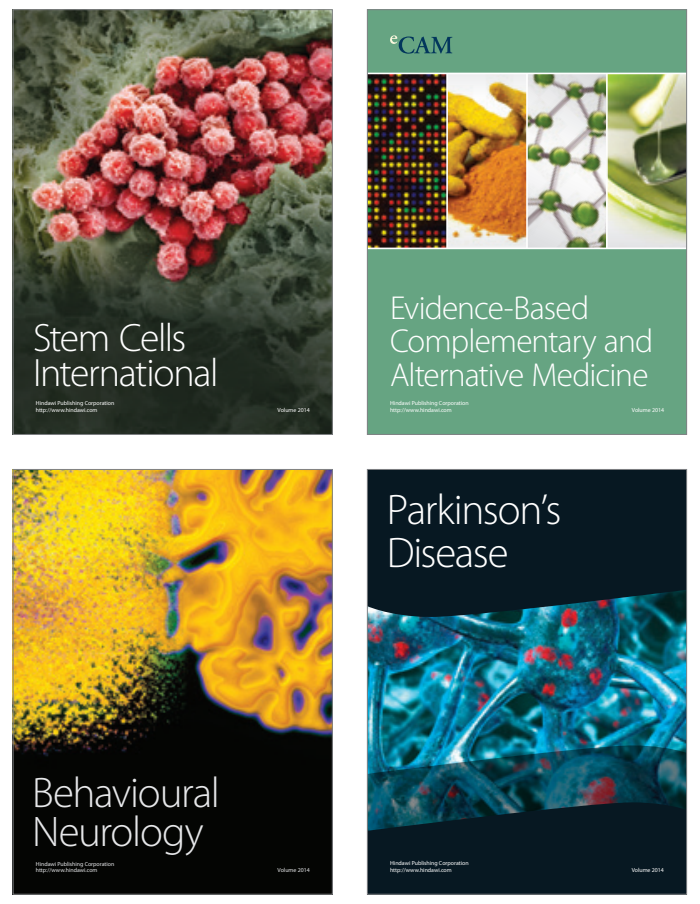
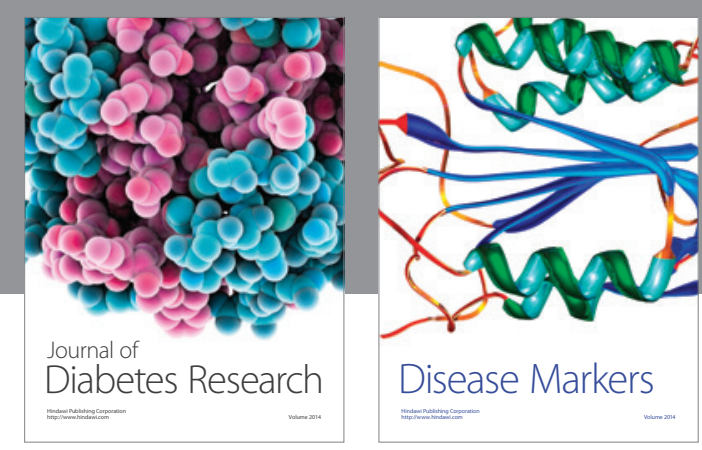

Disease Markers
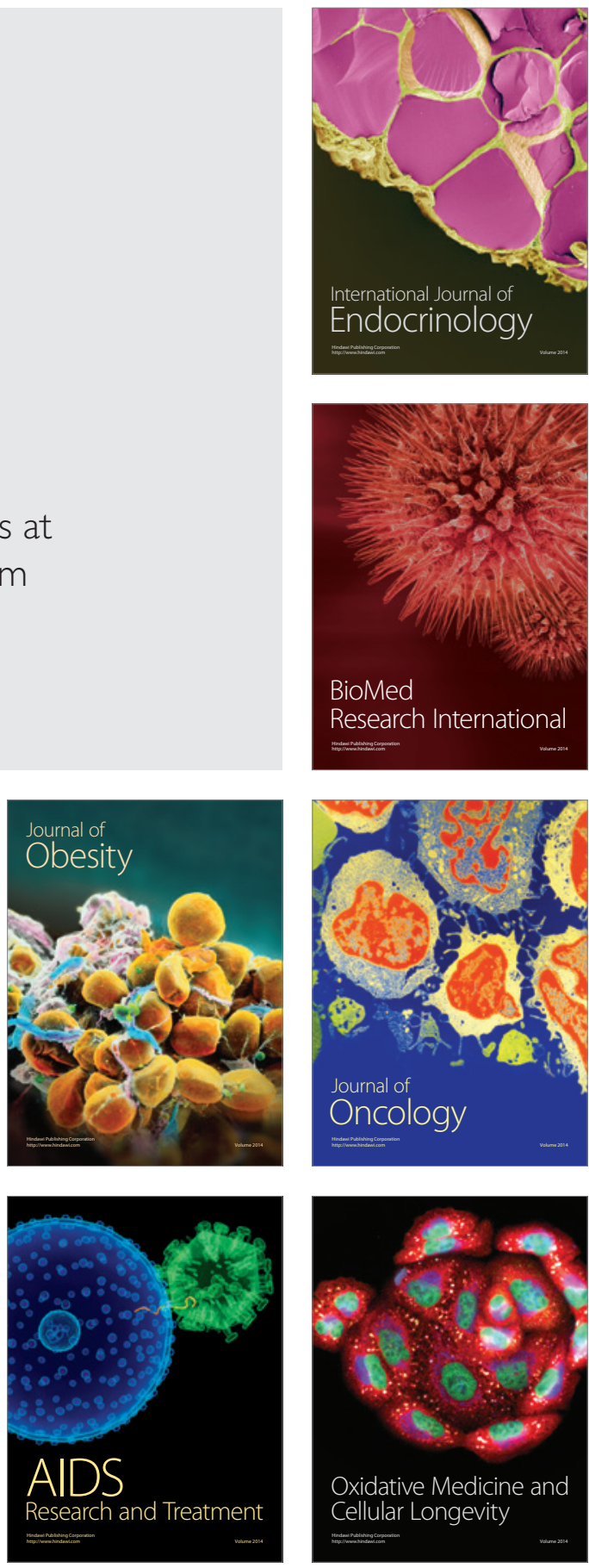